\title{
Novel FR-900493 Analogues That Inhibit the Outgrowth of Clostridium difficile Spores
}

\author{
Katsuhiko Mitachi, $^{\dagger}$ Hyun Gi Yun, ${ }^{\ddagger}$ Sara M. Kurosu, ${ }^{\dagger, \S}$ Shakiba Eslamimehr, ${ }^{\dagger}$ Maddie R. Lemieux, ${ }^{\dagger}$
} Lada Klaic, ${ }^{\ddagger}$ William M. Clemons, Jr., ${ }^{\ddagger}$ and Michio Kurosu* ${ }^{*}+\odot$

${ }^{\dagger}$ Department of Pharmaceutical Sciences, College of Pharmacy, University of Tennessee Health Science Center, 881 Madison Avenue, Memphis, Tennessee 38163, United States

${ }^{*}$ Division of Chemistry and Chemical Engineering, California Institute of Technology, 1200 E. California Blvd, Pasadena, California 91125, United States

Supporting Information

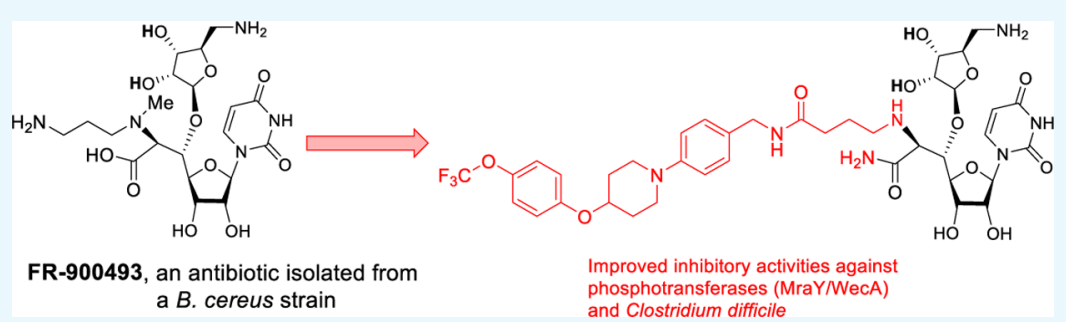

ABSTRACT: The spectrum of antibacterial activity for the nucleoside antibiotic FR-900493 (1) can be extended by chemical modifications. We have generated a small focused library based on the structure of 1 and identified UT-17415 (9), UT-17455 (10), UT-17460 (11), and UT-17465 (12), which exhibit anti-Clostridium difficile growth inhibitory activity. These analogues also inhibit the outgrowth of $C$. difficile spores at $2 \times$ minimum inhibitory concentration. One of these analogues, 11, relative to 1 exhibits over 180-fold and 15-fold greater activity against the enzymes, phospho-MurNAc-pentapeptide translocase (MraY) and polyprenyl phosphate-GlcNAc-1-phosphate transferase (WecA), respectively. The phosphotransferase inhibitor 11 displays antimicrobial activity against several tested bacteria including Bacillus subtilis, Clostridium spp., and Mycobacterium smegmatis, but no growth inhibitory activity is observed against the other Gram-positive and Gram-negative bacteria. The selectivity index (Vero cell cytotoxicity/C. difficileantimicrobial activity) of 11 is approximately 17 , and 11 does not induce hemolysis even at a $100 \mu \mathrm{M}$ concentration.

\section{INTRODUCTION}

Clostridium difficile, a Gram-positive bacterium, is transmitted by the fecal-oral route. C. difficile infection (CDI) can cause illness ranging from diarrhea, colitis, and toxic inflammatory bowel disease to death. $C$. difficile has become one of the most common causes of health care-associated infections in U.S. hospitals. ${ }^{1}$ Approximately 250000 people are hospitalized in the U.S. every year from CDI. ${ }^{2}$ The infective form of C. difficile is the spore, and its germination is the first committed step in CDI onset. $C$. difficile is found in abundance in the environment, and colonizes in the gut where it produces toxins that cause $C$. difficileassociated diarrhea (CDAD). ${ }^{3-5}$ Frequently, treatment with broad-spectrum antibiotic(s) has the adverse effect of increasing the incidence of recurrent CDIs because of the disruption of the normal balance of gut flora. ${ }^{6}$ A recently described highly toxic strain, $\mathrm{BI} / \mathrm{NAP} 1 / 027$, exhibits resistance to fluoroquinolones and produces $>20$ times more toxins than historical strains. ${ }^{7}$ Antibiotic treatment of CDI is difficult because of the antibiotic resistance and bacterial physiology (e.g., spore formation and protective effects of pseudomembranous colitis). ${ }^{8,9}$ Currently, there are only a limited number of drugs available for the treatment of $\mathrm{CDAD} .{ }^{10}$ Metronidazole and vancomycin are the primary therapy options for CDI. Vancomycin is recommended for severe infections that do not respond to metronidazole. Vancomycin, rifaximin, and fidaxomicin are used in recurrent or persistent cases. ${ }^{11}$ For severe recurrent CDIs, fecal microbiota transplantation, which involves instillation of stool from a healthy donor into the gastrointestinal (GI) tract of the patient, has been highlighted to restore the gut microbiome to a healthy state. ${ }^{12}$ At therapeutic concentrations, currently available drugs for the treatment of CDI are not effective in inhibiting the germination or outgrowth of $C$. difficile spores. Only fidaxomicin has been reported to inhibit spore production in C. difficile. ${ }^{13}$ To date, bile acid derivatives and a few organic molecules have been studied for their efficacy in the reduction of spore viability or inhibition of spore germination. ${ }^{14-19}$

In our continued efforts to identify strong inhibitors of bacterial phosphotransferases [phospho-MurNAc-pentapeptide translocase (translocase I or MraY) and polyprenyl phosphateGlcNAc-1-phosphate transferase (WecA)] (Figure 1), ${ }^{20-25}$ we

Received: November 7, 2017

Accepted: January 26, 2018

Published: February 9, 2018 
MraY-type phosphotransferase (A bacterial phosphotransferase, MurX in Mycobacterium spp.)

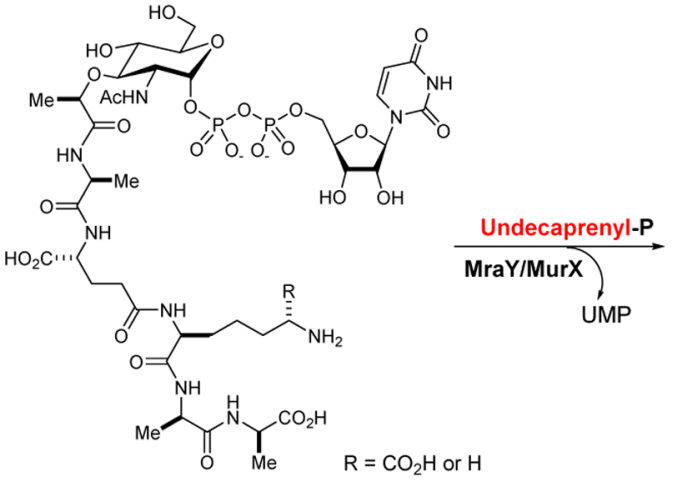

Park's nucleotide

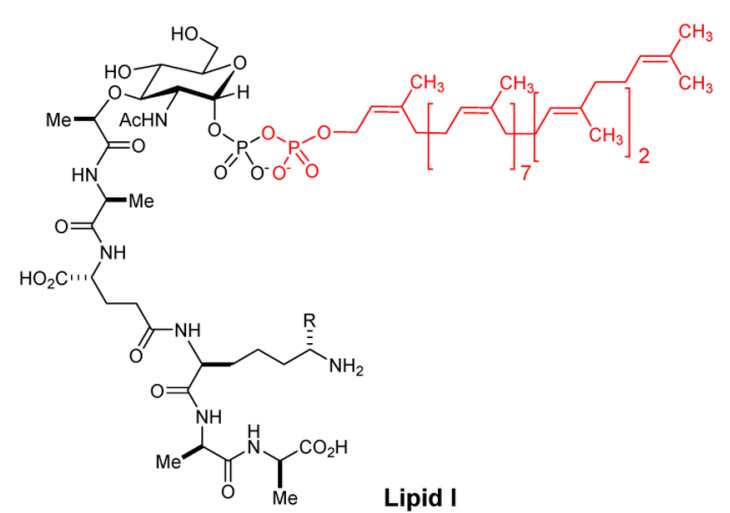

WecA-type phosphotransferase (A bacterial phosphotransferase, TagO or TarO in Gram-positive bacteria)

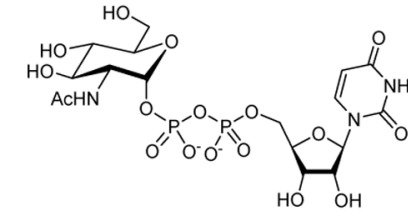

UDP-GICNAC

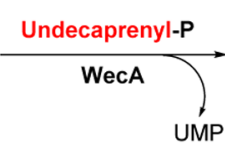

UMP

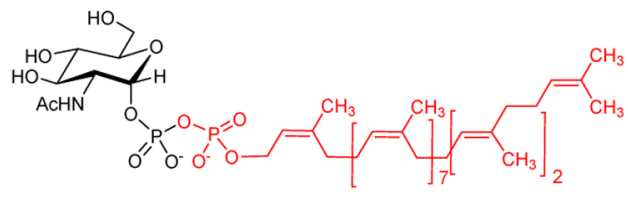

Glycolipid I (UndecaprenyI-P-P-GIcNAc)

UDP-GICNAC-dolichyl-phosphate $\mathrm{N}$-acetylglucosaminephosphotransferase (A human glycosyltransferase)

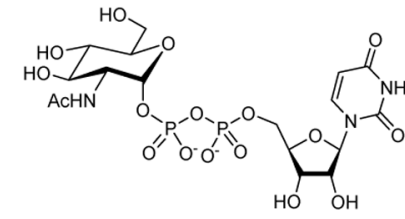

UDP-GICNAC

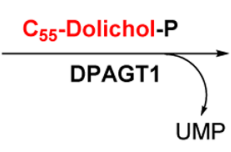

UMP

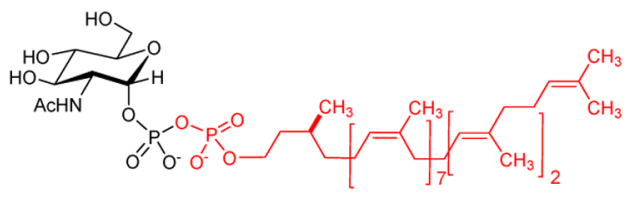

Dolichol-P-P-GIcNAc

Figure 1. Bacterial phosphotransferases and a human glycosyltransferase. MraY (MurX) is an established drug target for Gram-positive and Gramnegative bacterial infections. WecA is essential in the growth of Mycobacterium spp. and some Gram-positive bacteria (TagO or TarO). DPAGT1 is a human glycosyltransferase. Strong inhibition of DPAGT1 may cause cytotoxicity in mammalian cells.
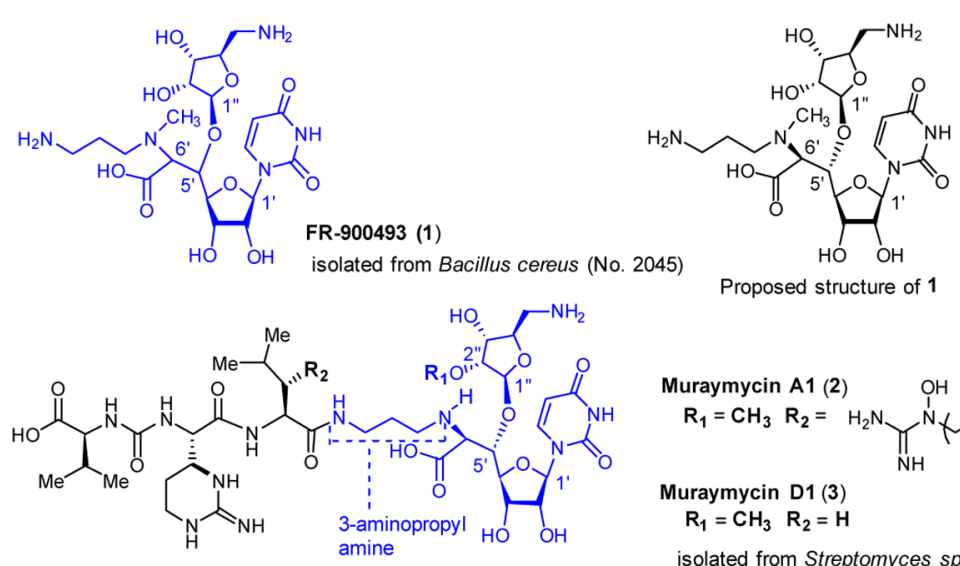

$$
\begin{aligned}
& \text { Muraymycin } \mathrm{A} 1 \text { (2) } \\
& \mathrm{R}_{\mathbf{1}}=\mathrm{CH}_{3} \mathrm{R}_{\mathbf{2}}=\mathrm{H}_{2} \mathrm{~N} \\
& \text { Muraymycin } \mathrm{D} \mathbf{1}(\mathbf{3}) \\
& \mathrm{R}_{\mathbf{1}}=\mathrm{CH}_{3} \mathrm{R}_{2}=\mathrm{H} \\
& \text { isolated from Streptomyces spp. }
\end{aligned}
$$

Figure 2. Structures of FR-900493 (1) and representative muraymycins, muraymycin A1 (2) and D1 (3). FR-900493 has only the right half of the muraymycins (the highlighted portion in blue). The unknown stereochemistries of the $5^{\prime}$ - and $6^{\prime}$-positions are determined unequivocally in this study.

have generated a small focused library based on the structure of the known MraY inhibitor FR-900493 (1, Figure 2) ${ }^{26}$ and assayed against the vegetative and spore forms of a $C$. difficile strain. MraY is specific for UDP- $N$-acetylmuramyl-pentapeptide (Park's nucleotide) forming undecaprenyl diphosphoryl- $N$ acetylmuramate-pentapeptide (lipid I). WecA and its homologues (e.g., TagO or TarO) in Gram-negative bacteria are responsible for the first step of wall teichoic acid synthesis that anchors the phospho-GlcNAc moiety of UDP-GlcNAc to undecaprenyl phosphate $\left(\mathrm{C}_{55}-\mathrm{P}\right)$. MraY enzymatic activity is essential for the growth of both Gram-positive and Gramnegative bacteria, and thus is considered as a target of interest for the discovery of novel antibacterial agents. The major source of MraY inhibitors resides in the nucleoside-based antibiotic group. This group has been subdivided into four classes: tunicamycins, ribosaminouridines, uridyl peptides, and capuramycins. Analysis 
Table 1. Inhibitory Activity of Bacterial Phosphotransferases (MraY and WecA) and C. difficile Growth by the C5' - and $6^{\prime}$ Diastereomers of FR-900493 ${ }^{a}$

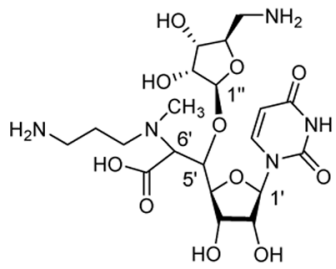

5'S,6' S-diastereomer (1) $5^{\prime} S, 6$ 'R-diastereomer (4) 5'R,6'S-diastereomer (5) $5^{\prime} R, 6^{\prime} R$-diastereomer $(6)$

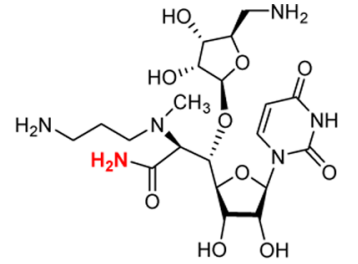

FR-900493-amide (7)

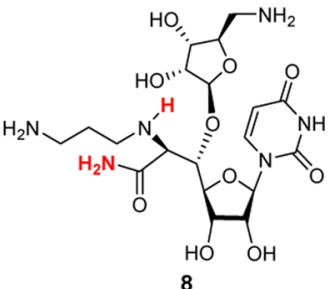

\begin{tabular}{|c|c|c|c|}
\hline compound & WecA inhibition $\mathrm{IC}_{50}(\mu \mathrm{M})^{b}$ & MraY inhibition $\mathrm{IC}_{50}(\mu \mathrm{M})^{c}$ & C. difficile ATCC $43596 \mathrm{MIC}(\mu \mathrm{g} / \mathrm{mL})^{d}$ \\
\hline FR-900493 (1) & $5.0 \pm 5.44$ & $25.0 \pm 8.67$ & $>25.0$ \\
\hline $5^{\prime} S, 6^{\prime} R$-diastereomer (4) & $>100$ & $>100$ & $>25.0$ \\
\hline $5^{\prime} R, 6^{\prime} S$-diastereomer (5) & $>100$ & $>100$ & $>25.0$ \\
\hline$S^{\prime} R, 6^{\prime} R$-diastereomer (6) & $>100$ & $>100$ & $>25.0$ \\
\hline FR-900493-amide (7) & $5.0 \pm 6.34$ & $25.0 \pm 9.67$ & $>25.0$ \\
\hline 8 & $>100$ & $>100$ & $>25.0$ \\
\hline tunicamycin & $0.15 \pm 7.80$ & $3.38 \pm 7.32$ & $>25.0$ \\
\hline
\end{tabular}

${ }^{a} \mathrm{WecA}$ and MraY assays (see the Supporting Information). ${ }^{b}$ E. coli WecA-containing membrane was used. ${ }^{c}$ Hydrogenivirga spp. MraY was used. ${ }^{d} \mathrm{~A}$ microdilution broth method was used.

of the pharmacological behaviors observed with several compounds in these classes shows a broad spectrum of antibacterial activity, including relevant drug-resistant strains, and in vivo efficacy without apparent toxicity. Ribosaminouridine antibiotics, which include muraymycin, liposidomycins, caprazamycin, and FR-900493 (1), exhibit the most promising biological profiles. ${ }^{27}$ On the other hand, essentiality of the WecA/TagO transferase subfamily is not completely understood in the growth of many bacteria. ${ }^{28,29}$ Only a few molecules have been reported to exhibit WecA inhibitory activity. ${ }^{28,29}$ Herein, we report a structure-activity relationship (SAR) obtained from a small focused library of FR-900493 (1) in a range of enzymes (MraY, WecA, and AglH) and bacterial growth inhibitory assays. Efficacy of these new MraY inhibitors against $C$. difficile spores along with in vitro toxicity assessments of the selected anti- $C$. difficile molecules is discussed.

\section{RESULTS AND DISCUSSION}

Chemistry and SAR of FR-900493. Aminoribosyl-uridyl peptide antibiotics such as FR-900493 (1) and muraymycins are an important class of natural products for the development of novel antibacterial agents. ${ }^{30,31}$ Chemical syntheses of $\mathbf{1}$ and muraymycin analogues are essential to perform exhaustive SAR studies. ${ }^{32}$ Muraymycin A1 (2) is one of the most active members of this family against both Gram-positive and Gram-negative bacteria. The fatty acid side chain $\left(\mathrm{R}_{2}\right)$ of 2 is critical for antimicrobial activity as muraymycin D1 (3) and the other related molecules lacking the $\mathrm{R}_{2}$ group are poorly active (Figure 2). ${ }^{25,33}$ Interestingly, we have demonstrated that muraymycin D1 shows strong bacteriostatic activity against Mycobacterium tuberculosis by targeting the bacterial phosphotransferases (MurX and WecA). ${ }^{25}$ Although FR-900493 (1) possesses only one half of the structure of the muraymycins, it displays antistaphylococcal activity [minimum inhibitory concentration (MIC) $3.13 \mu \mathrm{g} / \mathrm{mL}$ ] in vitro and in vivo. The $\mathrm{LD}_{50}$ value of 1 is over $500 \mathrm{mg} / \mathrm{kg}$, which was determined via intravenous administrations in mice, indicating that $\mathbf{1}$ is an ideal scaffold to develop into new antibacterial agents. ${ }^{26}$ It is interesting to note that $\mathbf{1}$ was isolated from the culture broth of Bacillus cereus (no.
2045), whereas other aminoribosyl-uridyl peptide antibiotics including muraymycins were isolated from Streptomyces spp..$^{31,33}$ Structurally, the C6'-amino group of FR-900493 is methylated, whereas O-methylation at the $\mathrm{C} 2{ }^{\prime \prime}$-position is observed in muraymycin A1 and D1. Absolute stereochemistries at the $\mathrm{C}^{\prime}$ and $C 6^{\prime}$-positions are speculated to be $5^{\prime} S$ and $6^{\prime} S$, respectively, based on the correlations with stereochemistries of muraymycins and structurally related molecules, caprazamycins. On the basis of the proposed structure, FR-900493 was first synthesized by Hirano and co-workers who only reported physical chemistry data (e.g., NMR and optical rotation) for the synthetic molecule. ${ }^{34}$ We have synthesized the four diastereomers of FR900493 with respect to the $\mathrm{C} 5^{\prime}$ - and $\mathrm{C6}^{\prime}$-stereocenters according to the synthetic scheme developed for muraymycin D1 (3) with minor modifications and compared their physical and biological data with those of the natural product. Chemical shifts and coupling constants of the $5^{\prime} S, 6^{\prime} S$-diastereomer 1 showed good agreement with those of the natural FR-900493 (see the Supporting Information). ${ }^{26}$ The four diastereomers of FR900493 were evaluated against the bacterial phosphotransferases MraY and WecA (Table 1). ${ }^{29,35}$

Surprisingly, 1 exhibited a weak MraY inhibitory activity $\left(\mathrm{IC}_{50}\right.$ $25.0 \mu \mathrm{M})$ but a moderate WecA inhibitory activity $\left(\mathrm{IC}_{50} 5.0 \mu \mathrm{M}\right)$. All unnatural diastereomers $(4,5$, and 6) did not display either MraY or WecA inhibitory activity, even at a $100 \mu \mathrm{M}$ concentration. The results of these enzymatic assays unequivocally determined the absolute stereochemistry of FR-900493 to be $5^{\prime} S$ and $6^{\prime} S$ configurations. We have observed that amidation of the C6'-carboxylic group in muraymycin D1 (3) does not decrease the MraY/WecA activity. ${ }^{25}$ Similarly, FR-900493-amide (7) exhibited an MraY/WecA inhibitory activity equal to that of 1. The $N$-methyl group of $\mathbf{1}$ is essential to inhibit the MraY and WecA enzymes; the de- $N$-methyl analogue 8 completely lost the MraY/WecA inhibitory activities. FR-900493 and its analogues shown in Table 1 were not effective in killing C. difficile (ATCC 43596 ) at $25.0 \mu \mathrm{g} / \mathrm{mL}$ or lower concentrations. As exemplified in the antibacterial activity of the muraymycin family molecules, ${ }^{30}$ the hydrophobic residues appended on the 3-aminopropylamine portion play a key role in selectivity and susceptibility against 
bacteria (Figure 2). We have generated a small forced library based on the core structures of 7 and 8 , and the generated molecules were assayed against $C$. difficile (ATCC 43596) at a single concentration of $50.0 \mu \mathrm{g} / \mathrm{mL}$. Four molecules $(9,10,11$, and 12) displayed anti-C. difficile activity (Table 2), and sufficient amounts of these molecules were resynthesized for thorough in vitro profiling.

Table 2. Inhibitory Activity of Bacterial Phosphotransferases (MraY and WecA) and C. difficile Growth by $9-12^{a}$

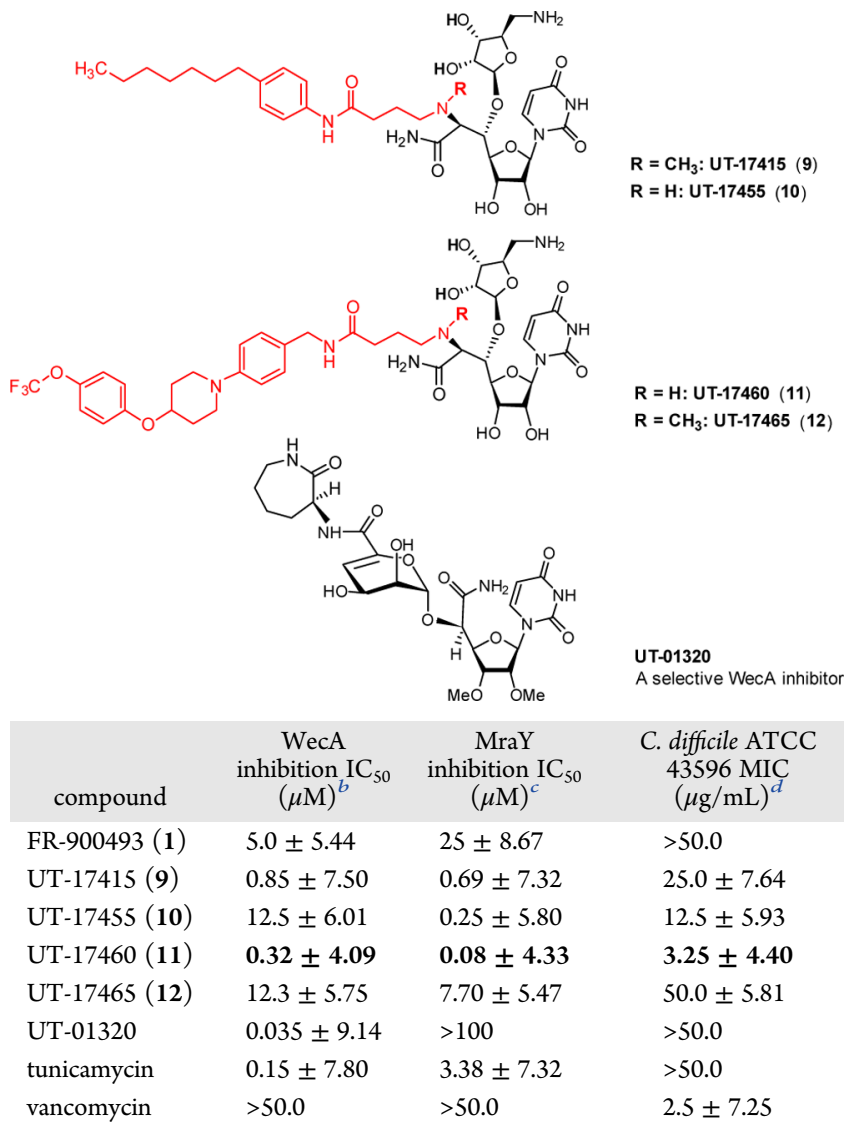

${ }^{a}$ WecA and MraY assays (see the Supporting Information). ${ }^{b}$ E. coli WecA-containing membrane was used. ${ }^{c}$ Hydrogenivirga spp. MraY was used. ${ }^{d} \mathrm{~A}$ microdilution broth method was used.

Syntheses of FR-900493 Analogues, 9, 10, 11, and 12. In our synthesis of muraymycin D1 (3), $\beta$-ribosylation of the C2ether-protected ribose donor $\left(\mathrm{R}_{1}=\mathrm{Me}\right.$ in 15) and Strecker reaction with mono-protected 1,3-diaminopropane to form secondary amine were performed stereoselectively. ${ }^{25}$ Our revised synthetic routes for FR-900493 analogues (9-12) are illustrated in Schemes 1 and 2. The monomethoxytetrachlorodiphenylmethoxymethyl (MTPM)-protected uridine 13 was prepared according to the previously reported procedure. ${ }^{36}$ The primary alcohol of 13 was oxidized by a modified Swern condition to provide the corresponding aldehyde in a quantitative yield, which was then subjected to Carreira's asymmetric alkynylation reaction using (-)- $N$-methylephedrine, ${ }^{37}$ furnishing the $(S)$ propargyl alcohol 14 in $80 \%$ yield with a selectivity of $>98: 2$. The stereochemistry of the secondary alcohol of $\mathbf{1 4}$ generated via Carreira's alkynylation was determined by the advanced Mosher's method (see the Supporting Information). ${ }^{38}$ The newly devised glycosyl donor $\mathbf{1 5}$ was designed to provide $\beta$ riboside whose protecting groups can be deprotected under mild acidic conditions. $\mathrm{N}$-Iodosuccinimide (NIS) $-\mathrm{AgBF}_{4}$-promoted ribosylation of $(S)$-propargyl alcohol 14 with 15 furnished the $\beta$ riboside $\mathbf{1 6}$ exclusively in $95 \%$ yield. ${ }^{23,25,39}$ The azido group of $\mathbf{1 6}$ was reduced with $\mathrm{Zn}$ metal in the presence of aq $\mathrm{NH}_{4} \mathrm{Cl}$, and the generated free-amine was protected with $(\mathrm{Boc})_{2} \mathrm{O}$ to furnish 17 in $90-92 \%$ overall yield. The alkyne moiety of 17 was subjected to a three-step procedure (partial reduction with a Lindlar catalyst, osmylation, and oxidative cleavage with $\left.\mathrm{Pb}(\mathrm{OAc})_{4}\right)$, providing the crude aldehyde 18. In a systematic screening of catalysts for Strecker reaction of $\mathbf{1 8}$ with the 4-aminobutanamide derivatives $\mathbf{1 9}$ (Scheme 1) or $\mathbf{2 0}$ (Scheme 2), it was realized that $(\mathrm{BnO})_{2} \mathrm{P}(\mathrm{O}) \mathrm{CH}_{2} \mathrm{P}(\mathrm{O})(\mathrm{OBn}) \mathrm{OH}$ provided a $\sim 4: 1$ mixture of the $6^{\prime} S$ - and $6^{\prime} R$-diastereomers $(21 S$ and $21 R)$ in greater than $80 \%$ yield. The desired diastereomer $21 S$ was subjected to hydration reaction with $\mathrm{HgCl}_{2}$-acetaldoxime to furnish the amide 22 in $95 \%$ overall yield. $N$-methylation of 22 was performed via reductive amination with paraformaldehyde and $\mathrm{NaB}(\mathrm{CN}) \mathrm{H}_{3}$ to afford $\mathbf{2 3}$ in 95\% yield. Global deprotection of $\mathbf{2 2}$ and $\mathbf{2 3}$ to form the desired products 9 and 10, respectively, was performed in a one-pot two-step reaction using $30 \%$ trifluoroacetic acid (TFA) followed by $80 \%$ TFA at $40{ }^{\circ} \mathrm{C}$; the crude products were purified by $\mathrm{C}_{18}$ reverse-phase high-performance liquid chromatography ( $\mathrm{HPLC})\left(\mathrm{MeOH} / \mathrm{H}_{2} \mathrm{O}=75: 25\right)$ to yield 9 and 10 in $85-90 \%$ yield. The stereochemistry of the $\mathrm{C}^{\prime}$-stereocenter for $21 \mathrm{~S}$ generated via Strecker reaction was unequivocally determined via its conformational analyses (see the Supporting Information). Similarly, the analogues $\mathbf{1 1}$ and $\mathbf{1 2}$ were synthesized with the primary amine $\mathbf{2 0}$ via the synthetic scheme developed for $\mathbf{9}$ and 10 (Scheme 2).

Enzyme and Bacterial Growth Inhibitory Activities of 9, 10, 11, and 12. Despite the extensive efforts to obtain membrane fractions from $C$. difficile (ATCC 43596), we could not obtain sufficient amounts of active $C$. difficile membrane containing MraY and WecA homolog. In this study, for assays, we used purified MraY from the thermophilic bacterium Hydrogenivirga (HyMraY) and the active membrane fraction (P-60) from Escherichia coli. Protein sequence alignment via BLAST ${ }^{40}$ of $H y \mathrm{MraY}$ and EcWecA against C. difficile (strain F501) revealed that MraY between Hydrogenivirga spp. and C. difficile showed $57 \%$ similarity/38\% identity and WecA/putative WecA homolog between $E$. coli and C. difficile showed $47 \%$ similarity/28\% identity. We previously confirmed that the activities of inhibitor molecules against $\mathrm{MraY}$ and WecA are similar across various species: Mycobacterium smegmatis, M. tuberculosis, E. coli, and Hydrogenivirga spp. ${ }^{21,29,35}$ The synthetic molecules (9, 10, 11, and 12) were evaluated against the phosphotransferases (MraY and WecA) and C. difficile strain (ATCC 43596) (Table 2). The $\mathrm{N}$-methyl analogues, 9 and 12, exhibited weak anti-C. difficile growth inhibitory activity, although their MraY inhibitory activities were over 30 - and 3-fold, respectively, more potent than that of FR-900493 (1). In sharp contrast, the de- $N$-methyl analogues, 10 and 11, were over 100 and 300-times more potent in the MraY inhibitory activity than 1 . The WecA inhibitory activity of 11 was $\sim 15$-fold more than that of 1 . Therefore, the anti-C. difficile activity of $\mathbf{1 1}$ is likely attributed to the inhibition of the MraY enzyme. This hypothesis was further supported by the fact that a selective WecA inhibitor, UT-01320, ${ }^{20}$ did not inhibit growth of $C$. difficile at $>50.0 \mu \mathrm{g} / \mathrm{mL}$ concentrations. The analogue $\mathbf{1 1}$ was identified to be a strong MraY/WecA inhibitor, whose activity was significantly better than that of a known $\mathrm{MraY} / \mathrm{WecA}$ inhibitor, tunicamycin. ${ }^{28,29,35}$ The anti- $C$. difficile activity is correlated with the enzyme inhibitory activity of MraY; 10 and 11 displayed MIC values of 12.5 and $3.25 \mu \mathrm{g} / \mathrm{mL}$, 
Scheme 1. Syntheses of Anti-C. difficile FR-900493 Analogues 9 and 10
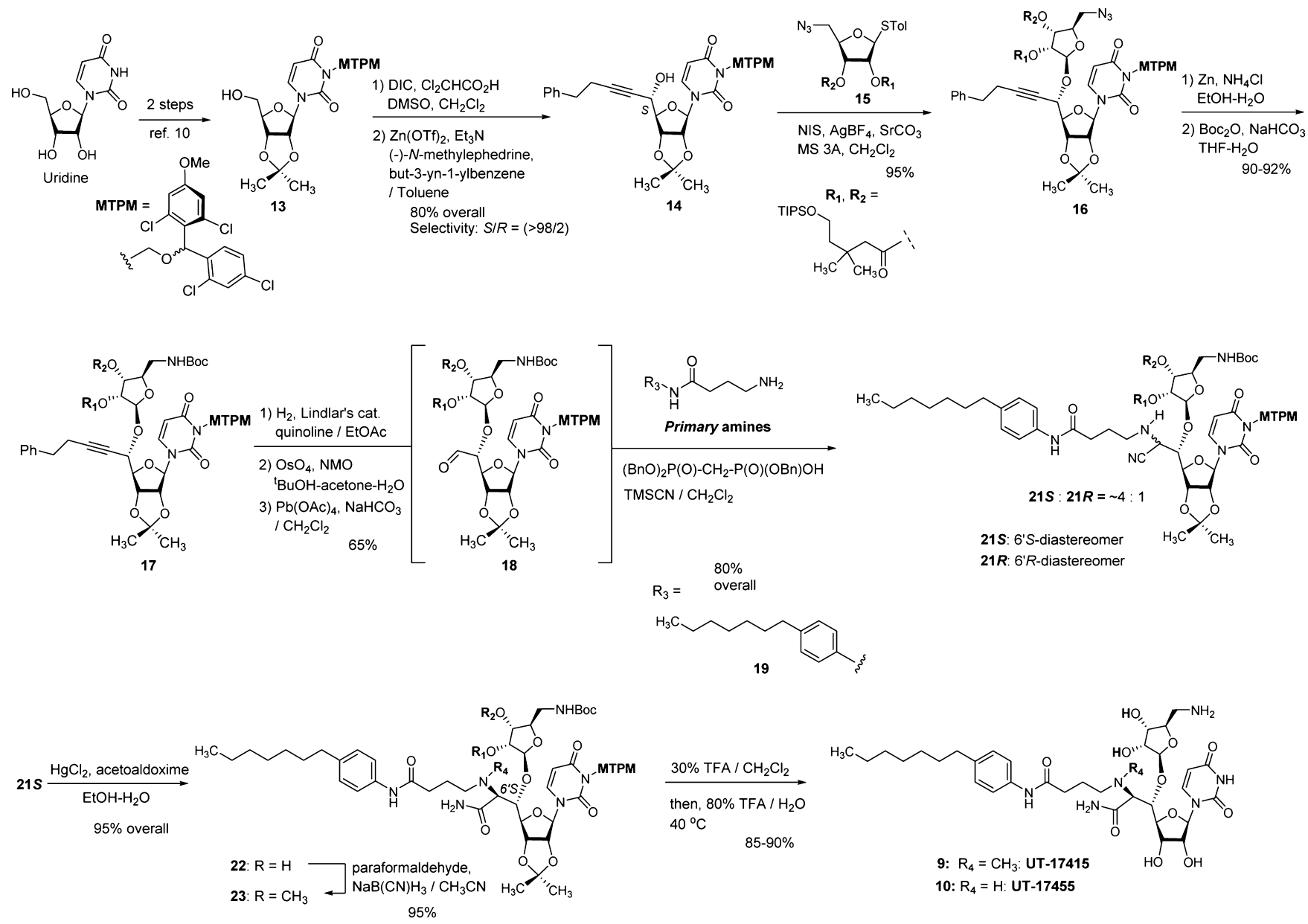

Scheme 2. Syntheses of Anti-C. difficile FR-900493 Analogues 11 and 12
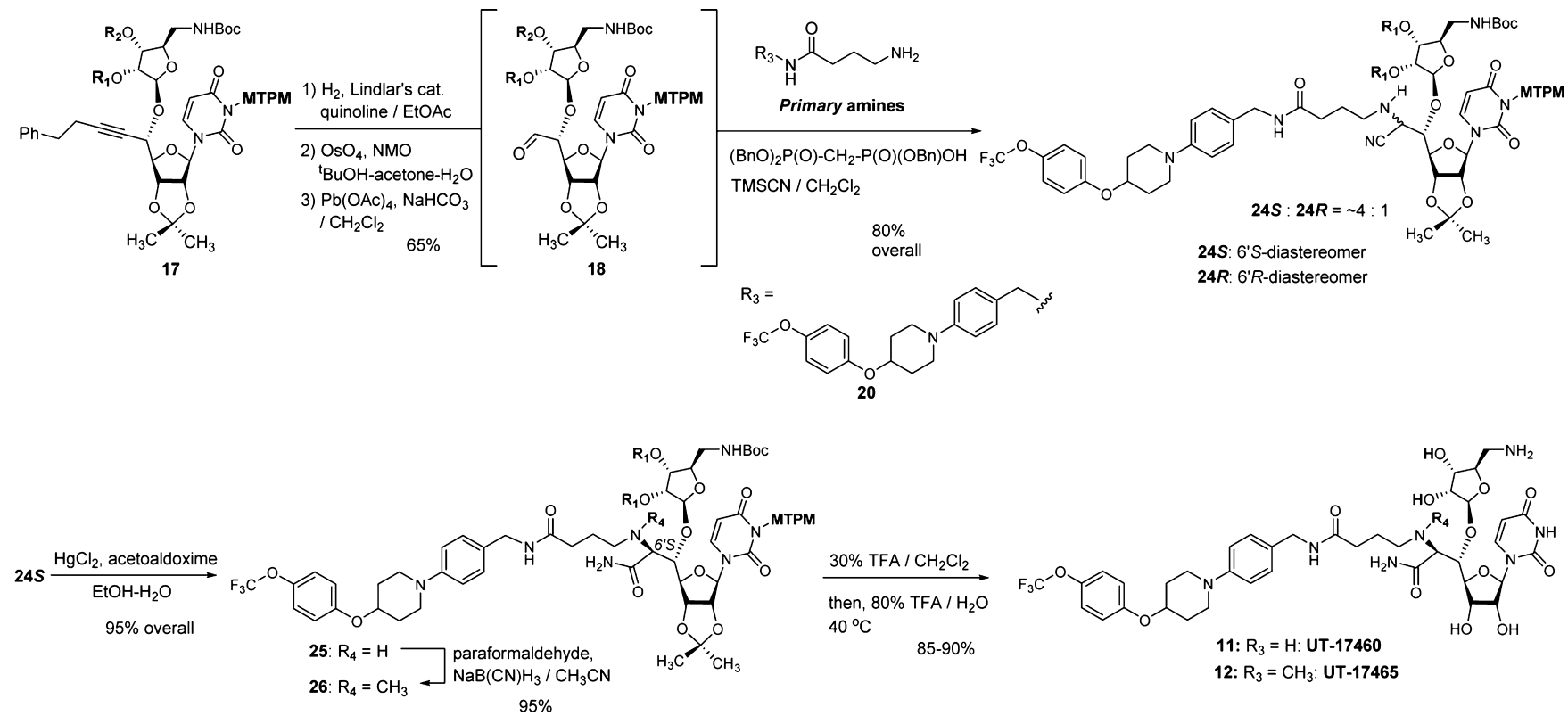

respectively, against C. difficile (e.g., an MIC of $2.50 \mu \mathrm{g} / \mathrm{mL}$ for vancomycin).

Effect of 9, 10, and 11 on C. difficile Spores. The effect of 9, 10, and 11 on $C$. difficile spores was determined by counting colony-forming units (CFUs) of the spore germination on taurocholate-containing agar plates after the treatment of the $C$. difficile spores with these analogues $(2 \times \mathrm{MIC})$ for $24 \mathrm{~h}$. C. difficile spores show resistance to most known anti-C. difficile agents. ${ }^{19}$ 
Indeed, in these studies, vancomycin, metronidazole, and linezolid did not inhibit the spore outgrowth, even at $5 \times$ MIC. On the contrary, the new MraY inhibitors 9, 10, and 11 prevented the outgrowth of the $C$. difficile spores into colonies at $2 \times$ MIC (Figure 3).

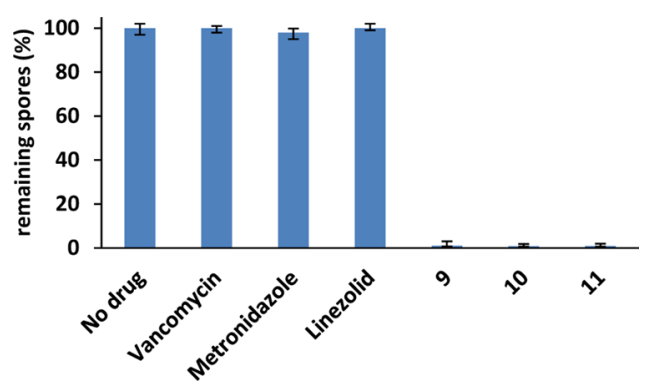

Figure 3. Viability of C. difficile (ATCC 43596) spores treated with the MraY inhibitors, 9, 10, and 11, and representative anti- $C$. difficile drugs. The spores treated with molecules $(2 \times$ or $5 \times \mathrm{MIC})$ in a BHI medium or saline $(24 \mathrm{~h})$ were plated on a $\mathrm{BHI}$ agar plate containing sodium taurocholate and incubated anaerobically for $48 \mathrm{~h}$. Vancomycin, metronidazole, and linezolid were treated with $5 \times \mathrm{MIC}$, and 9, 10, and 11 were treated with $2 \times$ MIC. Germinated spores were counted (CFUs) $(p \leq 0.05)$.

Physicochemical Properties and in Vitro Toxicity of 11. UT-17460 (11) exhibited pharmacological characteristics superior to those of UT-17455 (10); (1) water solubility of 11 $(22.0 \mathrm{mg} / \mathrm{mL})$ is 200 times greater than that of $10(0.11 \mathrm{mg} /$ $\mathrm{mL}$ ), (2) 11 is approximately 8 times less cytotoxic than $\mathbf{1 0}$ against Vero cells (African green monkey kidney epithelial cells, $\mathrm{IC}_{50} 65.0 \mu \mathrm{M}$ for 10), and (3) 11 showed relatively low induction of hemolysis $\left(\mathrm{IC}_{50} 205.6 \mu \mathrm{M}\right.$ ), whereas 10 lysed blood cells at a much lower concentration ( $\mathrm{IC}_{50} 70.0 \mu \mathrm{M}$ ) than 11 (Table 3). Thus, we selected $\mathbf{1 1}$ for further in vitro pharmacological evaluation. WecA enzyme inhibitors have the potential to interfere with a human homologue, dolichyl-phosphate GlcNAc1-phosphotransferase 1 (DPAGT1), which catalyzes the first step of the protein $\mathrm{N}$-glycosylation process in humans (Figure 1). Thus, strong inhibition of DPAGT1 may cause cytotoxicity in vitro and in vivo. ${ }^{41}$ We have established a counterselection assay using a thermophilic dolichyl-phosphate GlcNAc-1-phosphotransferase (AglH from Methanocaldococcus jannaschii) to assess the toxicity level of antibacterial phosphotransferase inhibitors (Table 3). Interestingly, 11 exhibited a relatively stronger $\mathrm{AglH}$ inhibitory activity $\left(\mathrm{IC}_{50} 3.61 \mu \mathrm{M}\right)$ than 10 and tunicamycin; however, the $\mathrm{IC}_{50}$ level of $\mathbf{1 1}$ against Vero cells was much higher than those of $\mathbf{1 0}$ and tunicamycin. The FR-900493 analogue 11 exhibited low permeability across Caco-2 epithelial monolayers $\left(P_{\text {app }}\right.$ rate coefficient $<1 \times 10^{-6} \mathrm{~cm} / \mathrm{s}$ ) with moderate efflux (an efflux ratio of 5.5), predicting that $\mathbf{1 1}$ is poorly absorbed from the GI tract.

Spectrum of Antibacterial Activity of 11. As summarized in Figure 4, UT-17460 (11) exhibited a very narrow spectrum of

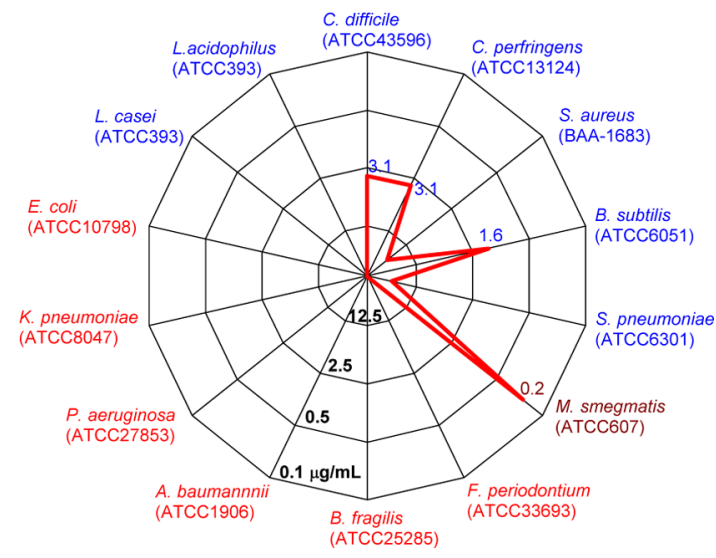

Figure 4. Antibacterial activity of UT-17460 (11, line in red).

antibacterial activity; 11 also killed the other Clostridium spp., Clostridium perfringens (MIC $3.1 \mu \mathrm{g} / \mathrm{mL}$ ), Bacillus subtilis (MIC $1.6 \mu \mathrm{g} / \mathrm{mL}$ ), and M. smegmatis (MIC $0.2 \mu \mathrm{g} / \mathrm{mL}$ ) but did not inhibit the growth of Lactobacillus spp., Staphylococcus aureus, Staphylococcus pneumoniae, and all Gram-negative bacteria tested at $25.0 \mu \mathrm{g} / \mathrm{mL}$ or higher concentrations.

\section{CONCLUSIONS}

FR-900493 (1) has long been known as an MraY inhibitor for which we have firmly established the stereochemistry. In our thorough enzyme inhibitory assays of the phosphotransferases, we concluded that the antibacterial activity of $\mathbf{1}$ is attributed to a combination of WecA and MraY inhibitory activities, but $\mathbf{1}$ is a weak MraY inhibitor $\left(\mathrm{IC}_{50} 25.0 \mu \mathrm{M}\right)$. Because WecA is not essential in the growth of many bacteria except for a few pathogens (e.g., Mycobacterium spp.), ${ }^{28,42}$ improving MraY inhibitory activity of 1 should be a beneficial direction to identify effective antibacterial agents. Stereochemistry of the $\mathrm{C}^{\prime}$ - and $\mathrm{C6}^{\prime}$-positions of 1 is required to be the natural configuration $\left(5^{\prime} S\right.$ and $6^{\prime} S$ ) to exhibit bacterial growth and $\mathrm{MraY} / \mathrm{Wec}$ enzyme inhibitory activities. The $\mathrm{C}^{\prime}-\mathrm{CO}_{2} \mathrm{H}$ group of $\mathbf{1}$ can be masked as its primary amide without decreasing $\mathrm{MraY} / \mathrm{WecA}$ activity; however, the $\mathrm{N}$-methyl group is essential for $\mathbf{1}$ to display phosphotransferase inhibitory activities. Muraymycins lack the $\mathrm{N}$-methyl group but exhibit a strong MraY enzyme inhibitory activity. Importantly, only the muraymycin analogues having a hydrophobic side chain [e.g., muraymycin A1 (2)] exhibit a strong antimicrobial activity. We have generated a small focused library based on the structures of 7 and $\mathbf{8}$ and screened against the

Table 3. Counterselection Assays Based on Prenyl phosphate-GlcNAc-1-phosphotransferases (WecA vs AglH) and in Vitro Cytotoxicities

\begin{tabular}{|c|c|c|c|c|c|}
\hline \multirow[b]{2}{*}{ compound } & \multicolumn{2}{|c|}{ WecA inhibition $\mathrm{IC}_{50}(\mu \mathrm{M})^{a}$} & \multirow[b]{2}{*}{ AglH inhibition $\mathrm{IC}_{50}(\mu \mathrm{M})^{a}$ M. jannaschii $\mathrm{AglH}$} & \multirow[b]{2}{*}{ Vero cells $\mathrm{IC}_{50}(\mu \mathrm{M})^{a}$} & \multirow[b]{2}{*}{$\begin{array}{c}\text { hemolysis } \mathrm{IC}_{50}(\mu \mathrm{M}) \text { sheep } \\
\text { blood }^{a}\end{array}$} \\
\hline & E. coli WecA & $\begin{array}{l}\text { M. smegmatis } \\
\text { WecA }\end{array}$ & & & \\
\hline UT-17455 (10) & $12.5 \pm 6.01$ & $12.5 \pm 5.42$ & $12.5 \pm 5.18$ & $7.08 \pm 5.67$ & $70 \pm 5.71$ \\
\hline UT-17460 (11) & $0.32 \pm 4.09$ & $0.25 \pm 4.84$ & $3.61 \pm 4.43$ & $65 \pm 4.65$ & $205.8 \pm 4.33$ \\
\hline tunicamycin & $0.15 \pm 7.80$ & $0.15 \pm 7.22$ & $13.27 \pm 8.10$ & $0.12 \pm 7.78$ & $15 \pm 7.83$ \\
\hline
\end{tabular}

${ }^{a}$ All assay procedures are described in the Supporting Information. 
vegetative form of $C$. difficile strain (ATCC 43596) under anaerobic conditions. We identified four anti-C. difficile FR900493 analogues, 9, 10, 11, and 12. These analogues were resynthesized via the synthetic procedures reported previously with modifications of selective ribosylation $(14 \rightarrow 16)$ and Strecker reactions $(\mathbf{1 8} \rightarrow \mathbf{2 1}$ and $\mathbf{2 4}$ ) (Schemes 1 and 2). The resynthesized analogues were characterized by $C$. difficile growth and the bacterial phosphotransferase inhibitory assays. The analogue 11 exhibited strong $\mathrm{MraY} / \mathrm{Wec} \mathrm{A}$ inhibitory activity ( $\mathrm{IC}_{50} 0.08$ and $0.30 \mu \mathrm{M}$, respectively) and killed the vegetative state of $C$. difficile with an MIC value of $3.25 \mu \mathrm{g} / \mathrm{mL}$. In vitro cytotoxicity level of $\mathbf{1 1}$ was much lower than those of tunicamycin and 10; although 11 inhibited $\mathrm{AglH}$ at low concentrations. Toxicity of tunicamycin and $\mathbf{1 0}$ in mammalian cells may be largely due to the membrane disruption as demonstrated by the hemolysis assay. On the other hand, the hemolytic activity of $\mathbf{1 1}$ is attenuated by the pharmacologically benign hydrophobic group. ${ }^{43}$ Interestingly, the MraY inhibitors 9, 10, and 11 inhibited the outgrowth of the $C$. difficile spores (endospores) at $2 \times$ MIC concentrations (Figure 3). The inhibitory mechanism of outgrowth of the spores by the MraY inhibitors is far from completely understood. Recently, a strong lipid II-binding antibacterial peptide, nisin, was reported to inhibit the viability of the $C$. difficile spores at high concentrations. ${ }^{44}$ The effect of fidaxomicin was also observed in the inhibition of the $C$. difficile spore outgrowth at high concentrations $\left(4.0-14 \mu \mathrm{g} / \mathrm{mL}, \mathrm{MIC}_{90} 0.5 \mu \mathrm{g} / \mathrm{mL}\right.$ against vegetative $C$. difficile). ${ }^{45}$ C. difficile spores are metabolically dormant and are known to exhibit impermeability to a wide range of organic molecules. ${ }^{46}$ Thus, organic molecules with a high molecular mass (e.g., $M_{\mathrm{w}}=881.3$ for 11) are not likely to permeate the spore walls and directly inhibit the viability of the spores. Certain peptides or nucleoside derivatives are recognized by the Bacillus anthracis germination machinery, increasing their susceptibility to geminated spores or outgrowing spores. ${ }^{47,48} \mathrm{On}$ the other hand, germination machineries of $C$. difficile spores remain less well-understood because of the significantly lower levels of homologues of the spore coat proteins than those of other well-studied bacteria (e.g., B. subtilis and B. anthracis). ${ }^{48}$ Recent studies demonstrated that $C$. difficile uses subtilisin-like serine proteases (Csp) that regulate spore germination. ${ }^{49}$ In $C$. difficile, $\mathrm{CspC}$ is likely to transmit the bile acid signal to CspB, which activates the spore cortex lytic enzyme (i.e., SleC) by cleavage of pro-SlecC. SlecC alters the structure of the spore cortex and induces Ca-dipicolinate release, which triggers the outgrowth of $C$. difficile spores. ${ }^{50}$ Our MraY inhibitors may be involved in the induction from the spore forms to the germinating state. The germinated or outgrowing spores require MraY, which will be inhibited by the new inhibitors 9-12. We are currently evaluating the effectiveness of structurally distinct $\mathrm{MraY}$ inhibitors against the $C$. difficile spores. Correlation of nucleoside-based MraY inhibitor and ability of the $C$. difficile spore germination are being investigated. In preliminary bacterial growth inhibitory assays against a series of bacteria, 11 displayed a very narrow-spectrum antibiotic activity (Figure 4), which is advantageous in the development of selective anti-C. difficile agents that do not disrupt the gut microbiota in humans. In addition, in vitro pharmacokinetic data obtained via the Caco-2 permeability assay may indicate that $\mathbf{1 1}$ is poorly absorbed from the GI tract, which may reduce the toxicity of $\mathbf{1 1}$ when given orally. Pharmacokinetics and oral bioavailability, susceptibility to clinically isolated $C$. difficile and in vivo efficacy of 11 (using preclinical animal models), and selectivity of antibacterial activity of 11 at higher concentrations $(1000 \mu \mathrm{g} / \mathrm{mL})$ are the object of future studies.

\section{EXPERIMENTAL SECTION}

Chemistry: General Information. All chemicals were purchased from commercial sources and used without further purification unless otherwise noted. Tetrahydrofuran (THF), $\mathrm{CH}_{2} \mathrm{Cl}_{2}$, and $\mathrm{N}, \mathrm{N}$-dimethylformamide were purified via an Innovative Technology's Pure-Solve System. All reactions were performed under an argon atmosphere. All stirring procedures were performed with an internal magnetic stirrer. Reactions were monitored by thin-layer chromatography (TLC) using $0.25 \mathrm{~mm}$ coated commercial silica gel plates (EMD, silica gel $\left.60 \mathrm{~F}_{254}\right)$. TLC spots were visualized by UV light at $254 \mathrm{~nm}$ or developed with ceric ammonium molybdate or anisaldehyde or copper sulfate or ninhydrin solutions by heating on a hot plate. Reactions were also monitored by using Shimadzu LCMS-2020 with the following solvents: A: $0.1 \%$ formic acid in water and B: acetonitrile. Flash chromatography was performed with SiliCycle silica gel (Purasil $60 \AA$, 230-400 mesh). Proton magnetic resonance $\left({ }^{1} \mathrm{H}\right.$ NMR) spectral data were recorded on 400 and $500 \mathrm{MHz}$ instruments. Carbon magnetic resonance $\left({ }^{13} \mathrm{C} \mathrm{NMR}\right)$ spectral data were recorded on 100 and $125 \mathrm{MHz}$ instruments. For all NMR spectra, chemical shifts $(\delta \mathrm{H}, \delta \mathrm{C})$ were quoted in parts per million (ppm) and $J$ values were quoted in $\mathrm{Hz} .{ }^{1} \mathrm{H}$ and ${ }^{13} \mathrm{C}$ NMR spectra were calibrated with a residual undeuterated solvent $\left(\mathrm{CDCl}_{3}: \delta \mathrm{H}=7.26 \mathrm{ppm}, \delta \mathrm{C}=77.16 \mathrm{ppm} ; \mathrm{CD}_{3} \mathrm{CN}: \delta \mathrm{H}\right.$ $=1.94 \mathrm{ppm}, \delta \mathrm{C}=1.32 \mathrm{ppm} ; \mathrm{CD}_{3} \mathrm{OD}: \delta \mathrm{H}=3.31 \mathrm{ppm}, \delta \mathrm{C}=$ 49.00 ppm; DMSO- $d_{6}: \delta \mathrm{H}=2.50 \mathrm{ppm}, \delta \mathrm{C}=39.52 \mathrm{ppm} ; \mathrm{D}_{2} \mathrm{O}$ : $\delta \mathrm{H}=4.79 \mathrm{ppm})$ as an internal reference. The following abbreviations were used to designate the multiplicities: $\mathrm{s}=$ singlet, $\mathrm{d}=$ doublet, $\mathrm{dd}=$ double doublets, $\mathrm{t}=$ triplet, $\mathrm{q}=$ quartet, quin $=$ quintet, hept $=$ heptet, $\mathrm{m}=$ multiplet, and $\mathrm{br}=$ broad . Infrared (IR) spectra were recorded on a PerkinElmer FT1600 spectrometer. HPLC analyses were performed with a Shimadzu LC-20AD HPLC system. All compounds were purified by reverse HPLC to be $\geq 95 \%$ purity. High-resolution mass spectrometry (HRMS) data were obtained from a Waters SYNAPT G2-Si (ion mobility mass spectrometer with nanoelectrospray ionization).

FR-900493 (1). ${ }^{1} \mathrm{H}$ NMR (400 MHz, $\left.\mathrm{D}_{2} \mathrm{O}\right) \delta: 7.79$ (d, $J=7.9$ $\mathrm{Hz}, 1 \mathrm{H}), 5.83$ (d, $J=7.8 \mathrm{~Hz}, 1 \mathrm{H}), 5.75(\mathrm{~d}, J=2.3 \mathrm{~Hz}, 1 \mathrm{H}), 5.20$ $(\mathrm{s}, 1 \mathrm{H}), 4.33$ (dd, $J=2.3,5.1 \mathrm{~Hz}, 1 \mathrm{H}), 4.28(\mathrm{dd}, J=2.3,8.4 \mathrm{~Hz}$, $1 \mathrm{H}), 4.23-4.19(\mathrm{~m}, 2 \mathrm{H}), 4.16(\mathrm{dd}, J=2.8,6.1 \mathrm{~Hz}, 1 \mathrm{H}), 4.13-$ $4.07(\mathrm{~m}, 2 \mathrm{H}), 3.49(\mathrm{~d}, J=8.3 \mathrm{~Hz}, 1 \mathrm{H}), 3.18(\mathrm{dd}, J=3.6,13.7 \mathrm{~Hz}$, $1 \mathrm{H}), 3.05-3.00(\mathrm{~m}, 3 \mathrm{H}), 2.88-2.83(\mathrm{~m}, 1 \mathrm{H}), 2.64-2.61(\mathrm{~m}$, $1 \mathrm{H}), 2.41(\mathrm{~s}, 3 \mathrm{H}), 1.94-1.88(\mathrm{~m}, 1 \mathrm{H}), 1.82-1.78(\mathrm{~m}, 1 \mathrm{H}) ;{ }^{13} \mathrm{C}$ NMR $\left(101 \mathrm{MHz}, \mathrm{D}_{2} \mathrm{O}\right) \delta$ : 175.72, 171.35, 155.21, 141.90, $110.08,102.46,91.42,83.74,80.76,78.53,75.41,74.20,71.41$, 71.34, 69.98, 52.35, 41.81, 39.02, 38.65, 24.99; HRMS (ESI ${ }^{+}$m/ $z$ : calcd for $\mathrm{C}_{20} \mathrm{H}_{34} \mathrm{~N}_{5} \mathrm{O}_{11}[\mathrm{M}+\mathrm{H}], 520.2255$; found, 520.2262 .

FR-900493-5'S, 6'R-Diastereomer (4). ${ }^{1} \mathrm{H}$ NMR (400 MHz, $\left.\mathrm{D}_{2} \mathrm{O}\right) \delta: 7.83(\mathrm{~d}, J=8.0 \mathrm{~Hz}, 1 \mathrm{H}), 5.90(\mathrm{~d}, J=8.3 \mathrm{~Hz}, 1 \mathrm{H}), 5.73(\mathrm{~d}$, $J=2.1 \mathrm{~Hz}, 1 \mathrm{H}), 5.25(\mathrm{~s}, 1 \mathrm{H}), 4.36(\mathrm{~d}, J=7.7 \mathrm{~Hz}, 1 \mathrm{H}), 4.28-4.19$ $(\mathrm{m}, 2 \mathrm{H}), 4.18(\mathrm{~d}, J=10.4 \mathrm{~Hz}, 1 \mathrm{H}), 4.12-4.06(\mathrm{~m}, 2 \mathrm{H}), 3.45(\mathrm{~d}, J$ $=10.4 \mathrm{~Hz}, 1 \mathrm{H}), 3.32(\mathrm{dd}, J=14.1,3.7 \mathrm{~Hz}, 1 \mathrm{H}), 3.15(\mathrm{dd}, J=13.9$, $5.6 \mathrm{~Hz}, 1 \mathrm{H}), 3.10-3.03(\mathrm{~m}, 3 \mathrm{H}), 2.97-2.87(\mathrm{~m}, 1 \mathrm{H}), 2.59-2.51$ $(\mathrm{m}, 1 \mathrm{H}), 2.43(\mathrm{~s}, 3 \mathrm{H}), 1.99-1.93(\mathrm{~m}, 1 \mathrm{H}), 1.87-1.77(\mathrm{~m}, 1 \mathrm{H})$; ${ }^{13} \mathrm{C}$ NMR $\left(101 \mathrm{MHz}, \mathrm{D}_{2} \mathrm{O}\right) \delta: 175.72,171.35,155.21,141.90$, $110.08,102.46,91.42,83.74,80.76,78.53,75.41,74.20,71.41$, 71.34, 69.98, 52.35, 41.81, 39.02, 38.65, 24.99; HRMS $\left(\mathrm{ESI}^{+}\right) \mathrm{m} /$ $z$ : calcd for $\mathrm{C}_{20} \mathrm{H}_{34} \mathrm{~N}_{5} \mathrm{O}_{11}[\mathrm{M}+\mathrm{H}]$, 520.2255; found, 520.2272. 
FR-900493-5' $R, 6^{\prime} S$-Diastereomer (5). ${ }^{1} \mathrm{H}$ NMR (400 MHz, $\left.\mathrm{D}_{2} \mathrm{O}\right) \delta: 7.68(\mathrm{~d}, J=8.2 \mathrm{~Hz}, 1 \mathrm{H}), 5.93(\mathrm{~d}, J=8.1 \mathrm{~Hz}, 1 \mathrm{H}), 5.77(\mathrm{~d}$, $J=4.3 \mathrm{~Hz}, 1 \mathrm{H}), 5.33(\mathrm{~s}, 1 \mathrm{H}), 4.50-4.44(\mathrm{~m}, 3 \mathrm{H}), 4.20-4.11(\mathrm{~m}$, $3 \mathrm{H}), 4.06(\mathrm{dd}, J=5.2,4.7 \mathrm{~Hz}, 1 \mathrm{H}), 3.61(\mathrm{~d}, J=6.9 \mathrm{~Hz}, 1 \mathrm{H}), 3.37$ $(\mathrm{d}, J=13.2 \mathrm{~Hz}, 1 \mathrm{H}), 3.13(\mathrm{dd}, J=13.2,8.7 \mathrm{~Hz}, 1 \mathrm{H}), 3.06(\mathrm{t}, J=$ $7.3 \mathrm{~Hz}, 2 \mathrm{H}), 2.84(\mathrm{dt}, J=13.5,6.6 \mathrm{~Hz}, 1 \mathrm{H}), 2.74(\mathrm{dt}, J=12.8,6.7$ $\mathrm{Hz}, 1 \mathrm{H}), 2.44$ (s, 3H), 1.89 (dq, $J=13.8,6.6 \mathrm{~Hz}, 2 \mathrm{H}) ;{ }^{13} \mathrm{C}$ NMR $\left(101 \mathrm{MHz}, \mathrm{D}_{2} \mathrm{O}\right) \delta: 175.72,171.35,155.21,141.90,110.08$, 102.46, 91.42, 83.74, 80.76, 78.53, 75.41, 74.20, 71.41, 71.34, 69.98, 52.35, 41.81, 39.02, 38.65, 24.99; HRMS $\left(\mathrm{ESI}^{+}\right) \mathrm{m} / z$ : calcd for $\mathrm{C}_{20} \mathrm{H}_{34} \mathrm{~N}_{5} \mathrm{O}_{11}[\mathrm{M}+\mathrm{H}]$, 520.2255; found, 520.2251.

FR-900493-5'R, 6'R-Diastereomer (6). ${ }^{1} \mathrm{H}$ NMR (400 MHz, $\left.\mathrm{D}_{2} \mathrm{O}\right) \delta: 7.67(\mathrm{~d}, J=8.0 \mathrm{~Hz}, 1 \mathrm{H}), 5.91(\mathrm{~d}, J=8.0 \mathrm{~Hz}, 1 \mathrm{H}), 5.78(\mathrm{~d}$, $J=5.2 \mathrm{~Hz}, 1 \mathrm{H}), 5.31(\mathrm{~s}, 1 \mathrm{H}), 4.49-4.44(\mathrm{~m}, 1 \mathrm{H}), 4.43(\mathrm{t}, J=5.3$ $\mathrm{Hz}, 2 \mathrm{H}), 4.16-4.07(\mathrm{~m}, 3 \mathrm{H}), 4.05(\mathrm{t}, J=5.3 \mathrm{~Hz}, 1 \mathrm{H}), 3.54(\mathrm{~d}, J=$ $7.3 \mathrm{~Hz}, 1 \mathrm{H}), 3.23$ (dd, $J=13.3,3.0 \mathrm{~Hz}, 1 \mathrm{H}), 3.10-2.98(\mathrm{~m}, 3 \mathrm{H})$, $2.80(\mathrm{dt}, J=13.3,6.7 \mathrm{~Hz}, 1 \mathrm{H}), 2.67(\mathrm{dt}, J=13.3,6.9 \mathrm{~Hz}, 1 \mathrm{H})$, $2.38(\mathrm{~s}, 3 \mathrm{H}), 1.86(\mathrm{dq}, J=13.9,7.1 \mathrm{~Hz}, 2 \mathrm{H})$; HRMS $\left(\mathrm{ESI}^{+}\right) \mathrm{m} / z$ : calcd for $\mathrm{C}_{20} \mathrm{H}_{34} \mathrm{~N}_{5} \mathrm{O}_{11}[\mathrm{M}+\mathrm{H}], 520.2255$; found, 520.2247 .

FR-900493-Amide (7). ${ }^{1} \mathrm{H}$ NMR (400 MHz, $\left.\mathrm{D}_{2} \mathrm{O}\right) \delta: 7.83$ (d, $J=8.1 \mathrm{~Hz}, 1 \mathrm{H}), 5.91(\mathrm{~d}, J=8.0 \mathrm{~Hz}, 1 \mathrm{H}), 5.72(\mathrm{~s}, 1 \mathrm{H}), 5.27(\mathrm{~s}$, $1 \mathrm{H}), 4.44-4.37(\mathrm{~m}, 1 \mathrm{H}), 4.32-4.25(\mathrm{~m}, 2 \mathrm{H}), 4.23(\mathrm{t}, J=6.5 \mathrm{~Hz}$, $1 \mathrm{H}), 4.20-4.14(\mathrm{~m}, 1 \mathrm{H}), 4.11(\mathrm{~d}, J=8.2 \mathrm{~Hz}, 1 \mathrm{H}), 3.68(\mathrm{dd}, J=$ $16.3,8.1 \mathrm{~Hz}, 1 \mathrm{H}), 3.43(\mathrm{~d}, J=14.0 \mathrm{~Hz}, 1 \mathrm{H}), 3.26(\mathrm{dd}, J=13.6,5.2$ $\mathrm{Hz}, 2 \mathrm{H}), 3.07(\mathrm{t}, J=7.3 \mathrm{~Hz}, 2 \mathrm{H}), 3.03-2.95(\mathrm{~m}, 1 \mathrm{H}), 2.64-2.56$ $(\mathrm{m}, 1 \mathrm{H}), 2.50(\mathrm{~s}, 3 \mathrm{H}), 2.04-1.94(\mathrm{~m}, 1 \mathrm{H}), 1.88-1.79(\mathrm{~m}, 1 \mathrm{H})$; ${ }^{13} \mathrm{C}$ NMR $\left(101 \mathrm{MHz}, \mathrm{D}_{2} \mathrm{O}\right) \delta: 175.72,171.35,155.21,141.90$, 110.08, 102.46, 91.42, 83.74, 80.76, 78.53, 75.41, 74.20, 71.41, 71.34, 69.98, 52.35, 41.81, 39.02, 38.65, 24.99; HRMS (ESI ${ }^{+}$m/ $z$ : calcd for $\mathrm{C}_{20} \mathrm{H}_{35} \mathrm{~N}_{6} \mathrm{O}_{10}[\mathrm{M}+\mathrm{H}]$, 519.2415; found, 519.2432. De N-Methyl FR-900493 (8). ${ }^{1} \mathrm{H}$ NMR $\left(400 \mathrm{MHz}, \mathrm{D}_{2} \mathrm{O}\right) \delta$ : $7.78(\mathrm{~d}, J=8.1 \mathrm{~Hz}, 1 \mathrm{H}), 5.89(\mathrm{~d}, J=7.8 \mathrm{~Hz}, 1 \mathrm{H}), 5.78(\mathrm{~d}, J=3.1$ $\mathrm{Hz}, 1 \mathrm{H}), 5.22(\mathrm{~s}, 1 \mathrm{H}), 4.40(\mathrm{dd}, J=5.5,3.2 \mathrm{~Hz}, 1 \mathrm{H}), 4.29(\mathrm{t}, J=$ $6.3 \mathrm{~Hz}, 1 \mathrm{H}), 4.22(\mathrm{dd}, J=6.8,5.1 \mathrm{~Hz}, 1 \mathrm{H}), 4.18(\mathrm{t}, J=4.5 \mathrm{~Hz}$, $1 \mathrm{H}), 4.16-4.08(\mathrm{~m}, 3 \mathrm{H}), 3.59(\mathrm{~d}, J=3.8 \mathrm{~Hz}, 1 \mathrm{H}), 3.28(\mathrm{~d}, J=$ $12.6 \mathrm{~Hz}, 1 \mathrm{H}), 3.11-3.02(\mathrm{~m}, 3 \mathrm{H}), 2.77(\mathrm{dt}, J=12.8,6.8 \mathrm{~Hz}, 1 \mathrm{H})$, $2.64\left(\mathrm{dt}, J=12.7,7.0 \mathrm{~Hz}, 1 \mathrm{H}\right.$ ), 1.83 (quin, $J=7.1 \mathrm{~Hz}, 2 \mathrm{H}$ ); ${ }^{13} \mathrm{C}$ NMR $\left(101 \mathrm{MHz}, \mathrm{D}_{2} \mathrm{O}\right) \delta: 175.72,171.35,155.21,141.90$, $110.08,102.46,91.42,83.74,80.76,78.53,75.41,74.20,71.41$, 71.34, 69.98, 52.35, 39.02, 38.65, 24.99; HRMS $\left(\mathrm{ESI}^{+}\right) \mathrm{m} / z$ : calcd for $\mathrm{C}_{19} \mathrm{H}_{33} \mathrm{~N}_{6} \mathrm{O}_{10}[\mathrm{M}+\mathrm{H}]$, 505.2258; found, 505.2277.

Synthesis of UT-17415 (9). To a stirred solution of 22 (2.9 $\mathrm{mg}, 1.6 \mu \mathrm{mol})$ in $\mathrm{CH}_{2} \mathrm{Cl}_{2}(0.70 \mathrm{~mL})$ was added TFA $(0.30 \mathrm{~mL})$. The reaction mixture was stirred for $2 \mathrm{~h}$ at room temperature (rt), and all volatiles were evaporated in vacuo. To a stirred solution of the crude mixture in $\mathrm{H}_{2} \mathrm{O}(0.2 \mathrm{~mL})$ was added TFA $(0.8 \mathrm{~mL})$. The reaction mixture was stirred for $4 \mathrm{~h}$ at $40{ }^{\circ} \mathrm{C}$, and all volatiles were evaporated in vacuo. The crude mixture was purified by silica gel column chromatography $\left(\mathrm{CHCl}_{3} / \mathrm{MeOH}\right.$ 80:20 to $\mathrm{CHCl}_{3} / \mathrm{MeOH} / \mathrm{H}_{2} \mathrm{O} / 50 \%$ aq ammonia $\left.56: 42: 7: 3\right)$ to afford UT-17415 (9) (1.2 mg, $1.6 \mu \mathrm{mol}, 100 \%)$ : TLC ( $n$ butanol/ethanol/ $\mathrm{CHCl}_{3} / 28 \%$ aq ammonia 4:7:2:7) $R_{\mathrm{f}}=0.55$; HPLC condition, column: Phenomenex Kinetex $1.7 \mu \mathrm{XB}-\mathrm{C} 18$ $100 \AA ̊ 0 \times 2.10 \mathrm{~mm}$ column, solvents: $80: 20 \mathrm{MeOH} / 0.05 \mathrm{M}$ $\mathrm{NH}_{4} \mathrm{HCO}_{3}$ in water, UV: $254 \mathrm{~nm}$; $[\alpha]_{\mathrm{D}}^{20}+0.038(c=0.12$, methanol); IR (thin film) $\nu_{\max }: 3333$ (br), 2955, 2926, 2855, $1676,1541,1515,1467,1413,1273,1204,1135,1063,1010,840$, $801,722 \mathrm{~cm}^{-1} ;{ }^{1} \mathrm{H}$ NMR (400 MHz, CD 3 OD) $\delta: 7.82(\mathrm{~d}, J=8.1$ $\mathrm{Hz}, 1 \mathrm{H}), 7.44$ (d, $J=8.0 \mathrm{~Hz}, 2 \mathrm{H}), 7.12$ (d, $J=8.1 \mathrm{~Hz}, 2 \mathrm{H}), 5.76$ $(\mathrm{d}, J=8.0 \mathrm{~Hz}, 1 \mathrm{H}), 5.70(\mathrm{~s}, 1 \mathrm{H}), 5.18(\mathrm{~s}, 1 \mathrm{H}), 4.58(\mathrm{~s}, 1 \mathrm{H}), 4.28$ $(\mathrm{d}, J=9.3 \mathrm{~Hz}, 1 \mathrm{H}), 4.21-4.16(\mathrm{~m}, 3 \mathrm{H}), 4.14-4.07(\mathrm{~m}, 3 \mathrm{H}), 3.61$ $(\mathrm{d}, J=9.4 \mathrm{~Hz}, 1 \mathrm{H}), 3.21(\mathrm{dd}, J=13.6,3.4 \mathrm{~Hz}, 1 \mathrm{H}), 2.83(\mathrm{td}, J=$ 12.1, 11.7, $5.0 \mathrm{~Hz}, 1 \mathrm{H}), 2.57(\mathrm{t}, J=7.6 \mathrm{~Hz}, 2 \mathrm{H}), 2.46(\mathrm{~s}, 3 \mathrm{H})$, $2.46-2.40(\mathrm{~m}, 2 \mathrm{H}), 2.00-1.89(\mathrm{~m}, 1 \mathrm{H}), 1.79(\mathrm{~d}, J=12.4 \mathrm{~Hz}$, $1 \mathrm{H}), 1.63-1.55(\mathrm{~m}, 2 \mathrm{H}), 1.37-1.23(\mathrm{~m}, 10 \mathrm{H}), 0.91-0.87(\mathrm{~m}$, $3 \mathrm{H}) ;{ }^{13} \mathrm{C}$ NMR (101 MHz, CD $\left.\mathrm{OD}\right) \delta: 173.86,172.29,142.40$, 140.18, 137.30, 129.69 (2C), 121.48 (2C), 112.07, 102.41, 92.48, $84.18,80.50,78.40,76.43,75.35,71.95,70.75,68.52,54.47$, $39.45,36.33,35.02,33.01,32.78,30.29,30.26,24.30,23.70$, 14.42; HRMS $\left(\mathrm{ESI}^{+}\right) \mathrm{m} / z$ : calcd for $\mathrm{C}_{34} \mathrm{H}_{53} \mathrm{~N}_{6} \mathrm{O}_{11}[\mathrm{M}+\mathrm{H}]$, 721.3772; found, 721.3761 .

Synthesis of UT-17455 (10). To a stirred solution of 21 (7.9 $\mathrm{mg}, 4.5 \mu \mathrm{mol})$ in $\mathrm{CH}_{2} \mathrm{Cl}_{2}(0.70 \mathrm{~mL})$ was added TFA $(0.30 \mathrm{~mL})$. The reaction mixture was stirred for $1 \mathrm{~h}$ at $\mathrm{rt}$, and all volatiles were evaporated in vacuo. To a stirred solution of the crude mixture in $\mathrm{H}_{2} \mathrm{O}(0.2 \mathrm{~mL})$ was added TFA $(0.8 \mathrm{~mL})$. The reaction mixture was stirred for $2 \mathrm{~h}$ at $40{ }^{\circ} \mathrm{C}$, and all volatiles were evaporated in vacuo. The crude mixture was purified by silica gel column chromatography $\left(\mathrm{CHCl}_{3} / \mathrm{MeOH} 80: 20\right.$ to $\mathrm{CHCl}_{3} /$ $\mathrm{MeOH} / \mathrm{H}_{2} \mathrm{O} / 50 \%$ aq ammonia 56:42:7:3) to afford UT-17455 (10) $(2.4 \mathrm{mg}, 3.4 \mu \mathrm{mol}, 76 \%)$ : TLC (n-butanol/ethanol/ $\mathrm{CHCl}_{3} / 28 \%$ aq ammonia 4:7:2:7) $R_{\mathrm{f}}=0.50$; HPLC condition: column: Phenomenex Kinetex 1.7 $\mu$ XB-C18 $100 \AA 150 \times 2.10$ mm column, solvents: 80:20 MeOH/0.05 $\mathrm{M} \mathrm{NH}_{4} \mathrm{HCO}_{3}$ in water, UV: $254 \mathrm{~nm}$; $[\alpha]_{\mathrm{D}}^{21}+0.538(c=0.24$, methanol); IR (thin film) $\nu_{\max }: 3302$ (br), 2955, 2926, 2855, 1672, 1605, 1542, 1515, $1466,1412,1271,1203,1185,1131,1111,1062,1010,819,721$ $\mathrm{cm}^{-1}$; ${ }^{1} \mathrm{H}$ NMR $\left(400 \mathrm{MHz}, \mathrm{CD}_{3} \mathrm{OD}\right) \delta: 7.77(\mathrm{~d}, J=8.1 \mathrm{~Hz}, 1 \mathrm{H})$, $7.43(\mathrm{~d}, J=8.1 \mathrm{~Hz}, 2 \mathrm{H}), 7.12(\mathrm{~d}, J=8.0 \mathrm{~Hz}, 2 \mathrm{H}), 5.74(\mathrm{~s}, 1 \mathrm{H})$, $5.73(\mathrm{~d}, J=12.6 \mathrm{~Hz}, 1 \mathrm{H}), 5.14(\mathrm{~s}, 1 \mathrm{H}), 4.21(\mathrm{dd}, J=4.7,4.2 \mathrm{~Hz}$, $1 \mathrm{H}), 4.19-4.13(\mathrm{~m}, 2 \mathrm{H}), 4.11(\mathrm{t}, J=4.7 \mathrm{~Hz}, 1 \mathrm{H}), 4.08(\mathrm{~s}, 2 \mathrm{H})$, $4.02-3.99(\mathrm{~m}, 1 \mathrm{H}), 3.50(\mathrm{~d}, J=8.9 \mathrm{~Hz}, 1 \mathrm{H}), 3.24(\mathrm{~d}, J=13.0 \mathrm{~Hz}$, $1 \mathrm{H}), 3.16-3.09(\mathrm{~m}, 1 \mathrm{H}), 2.73-2.60(\mathrm{~m}, 2 \mathrm{H}), 2.57(\mathrm{t}, J=7.7 \mathrm{~Hz}$, $2 \mathrm{H}), 2.43(\mathrm{dd}, J=7.4,4.0 \mathrm{~Hz}, 2 \mathrm{H}), 1.86$ (quin, $J=7.2 \mathrm{~Hz}, 2 \mathrm{H}$ ), 1.59 (quin, $J=6.4,5.7 \mathrm{~Hz}, 2 \mathrm{H}), 1.35-1.26(\mathrm{~m}, 8 \mathrm{H}), 0.92-0.87$ $(\mathrm{m}, 3 \mathrm{H}) ;{ }^{13} \mathrm{C}$ NMR $\left(101 \mathrm{MHz}, \mathrm{CD}_{3} \mathrm{OD}\right) \delta: 177.20,174.18$, $166.14,152.10,142.63,140.13,137.35,129.68$ (2C), 121.45 (2C), 110.58, 102.67, 92.49, 85.22, 80.48, 76.41, 75.02, 72.97, $71.23,64.28,43.15,36.34,35.45,33.01,32.78,30.29,26.60$, 23.70, 14.42; HRMS $\left(\mathrm{ESI}^{+}\right) \mathrm{m} / z$ : calcd for $\mathrm{C}_{33} \mathrm{H}_{51} \mathrm{~N}_{6} \mathrm{O}_{11}[\mathrm{M}+$ $\mathrm{H}$ ], 707.3616; found, 707.3624.

Synthesis of UT-17460 (11). To a stirred solution of 23 (5.3 $\mathrm{mg}, 2.7 \mu \mathrm{mol})$ in $\mathrm{CH}_{2} \mathrm{Cl}_{2}(0.70 \mathrm{~mL})$ was added TFA $(0.30 \mathrm{~mL})$. The reaction mixture was stirred for $1 \mathrm{~h}$ at $\mathrm{rt}$, and all volatiles were evaporated in vacuo. To a stirred solution of the crude mixture in $\mathrm{H}_{2} \mathrm{O}(0.2 \mathrm{~mL})$ was added TFA $(0.8 \mathrm{~mL})$. The reaction mixture was stirred for $2 \mathrm{~h}$ at $40{ }^{\circ} \mathrm{C}$, and all volatiles were evaporated in vacuo. The crude mixture was purified by silica gel column chromatography $\left(\mathrm{CHCl}_{3} / \mathrm{MeOH} 80: 20\right.$ to $\mathrm{CHCl}_{3} /$ $\mathrm{MeOH} / \mathrm{H}_{2} \mathrm{O} / 50 \%$ aq ammonia 56:42:7:3) to afford UT-17460 (11) $(2.2 \mathrm{mg}, 2.5 \mu \mathrm{mol}, 91 \%)$ : TLC (n-butanol/ethanol/ $\mathrm{CHCl}_{3} / 28 \%$ aq ammonia 4:7:2:7) $R_{\mathrm{f}}=0.50$; HPLC condition: column, Phenomenex Kinetex $1.7 \mu \mathrm{XB}-\mathrm{C} 18100 \AA 150 \times 2.10$ mm column, solvents: 75:25 MeOH/0.05 $\mathrm{M} \mathrm{NH}_{4} \mathrm{HCO}_{3}$ in water, UV: $254 \mathrm{~nm}$; $[\alpha]_{\mathrm{D}}^{21}+0.375(c=0.30$, methanol); IR (thin film) $\nu_{\max }: 3352$ (br), 2932, 1677, 1505, 1270, 1243, 1201, 1136, $1060,840,801,722 \mathrm{~cm}^{-1}$; ${ }^{1} \mathrm{H}$ NMR $\left(400 \mathrm{MHz}, \mathrm{CD}_{3} \mathrm{OD}\right) \delta: 7.78$ (d, $J=8.1 \mathrm{~Hz}, 1 \mathrm{H}), 7.18$ (dd, $J=9.0,3.5 \mathrm{~Hz}, 4 \mathrm{H}), 7.00$ (dd, $J=$ 16.0, $8.6 \mathrm{~Hz}, 4 \mathrm{H}), 5.77(\mathrm{~d}, J=2.9 \mathrm{~Hz}, 1 \mathrm{H}), 5.73(\mathrm{~d}, J=8.1 \mathrm{~Hz}$, $1 \mathrm{H}), 5.14(\mathrm{~s}, 1 \mathrm{H}), 4.57-4.50(\mathrm{~m}, 1 \mathrm{H}), 4.28(\mathrm{~s}, 2 \mathrm{H}), 4.22-4.13$ $(\mathrm{m}, 3 \mathrm{H}), 4.10(\mathrm{dd}, J=8.6,4.4 \mathrm{~Hz}, 1 \mathrm{H}), 4.07-3.98(\mathrm{~m}, 2 \mathrm{H})$, $3.52-3.46(\mathrm{~m}, 3 \mathrm{H}), 3.44(\mathrm{~d}, J=8.8 \mathrm{~Hz}, 1 \mathrm{H}), 3.17(\mathrm{~d}, J=13.0 \mathrm{~Hz}$, $1 \mathrm{H}), 3.14-3.02(\mathrm{~m}, 3 \mathrm{H}), 2.60(\mathrm{ddq}, J=18.4,11.8,6.9 \mathrm{~Hz}, 2 \mathrm{H})$, $2.29(\mathrm{td}, J=7.3,2.8 \mathrm{~Hz}, 2 \mathrm{H}), 2.12(\mathrm{dd}, J=14.5,5.6 \mathrm{~Hz}, 2 \mathrm{H})$, $1.93-1.73(\mathrm{~m}, 4 \mathrm{H}), 1.39-1.25(\mathrm{~m}, 2 \mathrm{H}) ;{ }^{13} \mathrm{C}$ NMR (101 MHz, $\left.\mathrm{CD}_{3} \mathrm{OD}\right) \delta: 175.58,166.16,157.62,152.01,142.55,131.22$, 
129.62 (2C), 123.56 (2C), 118.11 (2C), 118.07 (2C), 110.51, 102.67, 92.31, 85.27, 81.41, 80.43, 76.47, 75.08, 74.07 (2C), 73.01, 71.26, 64.44, 43.72, 43.62, 34.66, 31.48, 26.89; HRMS $\left(\right.$ ESI $\left.^{+}\right) \mathrm{m} / z$ : calcd for $\mathrm{C}_{39} \mathrm{H}_{51} \mathrm{~F}_{3} \mathrm{~N}_{7} \mathrm{O}_{13}[\mathrm{M}+\mathrm{H}], 882.3497$; found, 882.3512 .

UT-17465 (12). To a stirred solution of $24(4.7 \mathrm{mg}, 2.4 \mu \mathrm{mol})$ in $\mathrm{CH}_{2} \mathrm{Cl}_{2}(0.70 \mathrm{~mL})$ was added TFA $(0.30 \mathrm{~mL})$. The reaction mixture was stirred for $2 \mathrm{~h}$ at $\mathrm{rt}$, and all volatiles were evaporated in vacuo. To a stirred solution of the crude mixture in $\mathrm{H}_{2} \mathrm{O}(0.2$ $\mathrm{mL})$ was added TFA $(0.8 \mathrm{~mL})$. The reaction mixture was stirred for $4 \mathrm{~h}$ at $40^{\circ} \mathrm{C}$, and all volatiles were evaporated in vacuo. The crude mixture was purified by silica gel column chromatography ( $\mathrm{CHCl}_{3} / \mathrm{MeOH}$ 80:20 to $\mathrm{CHCl}_{3} / \mathrm{MeOH} / \mathrm{H}_{2} \mathrm{O} / 50 \%$ aq ammonia 56:42:7:3) to afford UT-17465 (12) $(2.0 \mathrm{mg}, 2.2 \mu \mathrm{mol}$, 92\%): TLC ( $n$-butanol/ethanol/ $\mathrm{CHCl}_{3} / 28 \%$ aq ammonia 4:7:2:7) $R_{\mathrm{f}}=0.55$; HPLC condition: column: Phenomenex Kinetex $1.7 \mu \mathrm{XB}-\mathrm{C} 18100 \AA 150 \times 2.10 \mathrm{~mm}$ column, solvents: 70:30 MeOH/0.05 $\mathrm{M} \mathrm{NH}_{4} \mathrm{HCO}_{3}$ in water, UV: $254 \mathrm{~nm}$; $[\alpha]_{\mathrm{D}}^{20}$ $+0.246\left(c=0.24\right.$, methanol); IR (thin film) $\nu_{\max }: 3276(\mathrm{br}), 2933$, $1675,1505,1465,1424,1271,1243,1199,1111 \mathrm{~cm}^{-1} ;{ }^{1} \mathrm{H}$ NMR $\left(400 \mathrm{MHz}, \mathrm{CD}_{3} \mathrm{OD}\right) \delta: 7.84(\mathrm{~d}, J=7.7 \mathrm{~Hz}, 1 \mathrm{H}), 7.19(\mathrm{dd}, J=8.5$, $3.3 \mathrm{~Hz}, 4 \mathrm{H}), 7.01(\mathrm{dd}, J=13.1,8.6 \mathrm{~Hz}, 4 \mathrm{H}), 5.86(\mathrm{~d}, J=7.8 \mathrm{~Hz}$, $1 \mathrm{H}), 5.73(\mathrm{~d}, J=2.4 \mathrm{~Hz}, 1 \mathrm{H}), 5.16(\mathrm{~s}, 1 \mathrm{H}), 4.54(\mathrm{tt}, J=7.3,3.1$ $\mathrm{Hz}, 1 \mathrm{H}), 4.30-4.25(\mathrm{~m}, 3 \mathrm{H}), 4.26(\mathrm{~d}, J=9.2 \mathrm{~Hz}, 1 \mathrm{H}), 4.22-4.05$ $(\mathrm{m}, 6 \mathrm{H}), 3.70(\mathrm{~d}, J=9.2 \mathrm{~Hz}, 1 \mathrm{H}), 3.52-3.44(\mathrm{~m}, 2 \mathrm{H}), 3.09$ (ddt, $J=12.3,8.6,4.3 \mathrm{~Hz}, 2 \mathrm{H}), 2.91-2.82(\mathrm{~m}, 1 \mathrm{H}), 2.58-2.53(\mathrm{~m}$, $1 \mathrm{H}), 2.50(\mathrm{~s}, 3 \mathrm{H}), 2.30(\mathrm{q}, J=6.9 \mathrm{~Hz}, 2 \mathrm{H}), 2.15-2.08(\mathrm{~m}, 2 \mathrm{H})$, $1.96-1.82(\mathrm{~m}, 3 \mathrm{H}), 1.81-1.71(\mathrm{~m}, 1 \mathrm{H}), 1.39-1.25(\mathrm{~m}, 2 \mathrm{H}) ;{ }^{13} \mathrm{C}$ NMR $\left(101 \mathrm{MHz}, \mathrm{CD}_{3} \mathrm{OD}\right) \delta: 175.34,172.18,157.63,151.97$, $142.38,131.33,129.66(2 \mathrm{C}), 123.55$ (2C), $118.12(2 \mathrm{C}), 118.08$ (2C), $111.86,92.05,84.35,80.28,78.36,76.42,75.37,74.08$ (2C), 71.54, 70.80, 68.28, 43.73, 39.72, 34.50, 31.48 (2C), 24.52; HRMS $\left(\mathrm{ESI}^{+}\right) \mathrm{m} / z$ : calcd for $\mathrm{C}_{40} \mathrm{H}_{53} \mathrm{~F}_{3} \mathrm{~N}_{7} \mathrm{O}_{13}[\mathrm{M}+\mathrm{H}]$, 896.3653; found, 896.3640.

MTPM-Protected Uridine 13. The MTPM-protected uridine 13 was synthesized according to the reported procedure. ${ }^{24,34}$ TLC (hexane/EtOAc 33:67) $R_{\mathrm{f}}=0.50 ;[\alpha]_{\mathrm{D}}^{22}-2.315(c=8.98$, $\mathrm{CHCl}_{3}$ ); IR (thin film) $\nu_{\text {max }}: 3478$ (br), 3057, 2986, 2940, 1715, 1663, 1598, 1556, 1455, 1374, 1265, 1212, 1066, 1039, 853, 808, 787, 732, $702 \mathrm{~cm}^{-1} ;{ }^{1} \mathrm{H}$ NMR $\left(400 \mathrm{MHz}, \mathrm{CDCl}_{3}\right) \delta: 7.51$ (ddd, $J$ $=17.3,8.5,0.7 \mathrm{~Hz}, 1 \mathrm{H}), 7.33-7.27(\mathrm{~m}, 2 \mathrm{H}), 7.18(\mathrm{ddd}, J=8.8$, $6.9,2.1 \mathrm{~Hz}, 1 \mathrm{H}), 6.85(\mathrm{~d}, J=5.1 \mathrm{~Hz}, 2 \mathrm{H}), 6.51(\mathrm{~d}, J=3.7 \mathrm{~Hz}, 1 \mathrm{H})$, $5.72(\mathrm{dd}, J=8.1,4.0 \mathrm{~Hz}, 1 \mathrm{H}), 5.60-5.51(\mathrm{~m}, 2 \mathrm{H}), 5.48(\mathrm{dd}, J=$ 12.6, $2.1 \mathrm{~Hz}, 1 \mathrm{H}), 4.95-4.93(\mathrm{~m}, 1 \mathrm{H}), 4.92(\mathrm{t}, J=2.4 \mathrm{~Hz}, 1 \mathrm{H})$, $4.30-4.25(\mathrm{~m}, 1 \mathrm{H}), 3.89$ (ddd, $J=11.7,9.1,2.6 \mathrm{~Hz}, 1 \mathrm{H}), 3.82-$ $3.73(\mathrm{~m}, 4 \mathrm{H}), 1.57(\mathrm{~s}, 3 \mathrm{H}), 1.36(\mathrm{~d}, J=2.4 \mathrm{~Hz}, 3 \mathrm{H}) ;{ }^{13} \mathrm{C} \mathrm{NMR}$ $\left(101 \mathrm{MHz}, \mathrm{CDCl}_{3}\right) \delta: 162.10,162.05,159.51,150.97,150.91$, $141.55,141.31,136.88,135.28,135.22,134.02,134.00,133.84$, $133.71,131.17,129.38,126.22,126.18,125.44,125.40,115.33$, $114.29,114.26,102.05,102.01,97.16,96.82,87.15,87.06,83.76$, 83.65, 80.29, 69.50, 62.76, 62.72, 55.69, 27.25, 25.25; HRMS $\left(\mathrm{ESI}^{+}\right) \mathrm{m} / z$ : calcd for $\mathrm{C}_{27} \mathrm{H}_{26} \mathrm{~N}_{2} \mathrm{O}_{8} \mathrm{NaCl}_{4}[\mathrm{M}+\mathrm{Na}]$, 669.0341; found, 669.0324 .

Propargyl Alcohol 14. To a stirred solution of 13 (1.54 g, 2.37 $\mathrm{mmol})$ and dichloroacetic acid $(0.29 \mathrm{~mL}, 3.56 \mathrm{mmol})$ in $\mathrm{CH}_{2} \mathrm{Cl}_{2}$ $(11.9 \mathrm{~mL})$ and DMSO $(2.37 \mathrm{~mL})$ was added $N, N^{\prime}$ diisopropylcarbodiimide $(0.56 \mathrm{~mL}, 3.56 \mathrm{mmol})$ at $0{ }^{\circ} \mathrm{C}$, and the reaction mixture was warmed to rt. After $8 \mathrm{~h}$, the reaction was quenched with saturated aq $\mathrm{NaHCO}_{3}$ and extracted with EtOAc. The combined organic extracts were dried over $\mathrm{Na}_{2} \mathrm{SO}_{4}$ and concentrated in vacuo. The precipitates were filtered, and the crude mixture was used for the next reaction without purification. To a suspension of $\mathrm{Zn}(\mathrm{OTf})_{2}$ (3.45 g, $9.48 \mathrm{mmol}$ ) and (+)-N- methylephedrine $(1.70 \mathrm{~g}, 9.48 \mathrm{mmol})$ in toluene $(7.1 \mathrm{~mL})$ was added $\mathrm{Et}_{3} \mathrm{~N}(1.32 \mathrm{~mL}, 9.48 \mathrm{mmol})$ at rt. After $3 \mathrm{~h}$, 4-phenyl-1butyne $(1.33 \mathrm{~mL}, 9.48 \mathrm{mmol})$ was added. After $4 \mathrm{~h}$, a solution of the crude aldehyde in toluene $(5 \mathrm{~mL})$ was added. The reaction mixture was stirred for $15 \mathrm{~h}$, quenched with saturated aq $\mathrm{NaHCO}_{3}$, and extracted with EtOAc. The combined organic extracts were dried over $\mathrm{Na}_{2} \mathrm{SO}_{4}$ and concentrated in vacuo. The crude mixture was purified by silica gel column chromatography (hexane/EtOAc 60:40 to 50:50) to afford $14(1.48 \mathrm{~g}, 1.90 \mathrm{mmol}$, $80 \%$ for 2 steps): TLC (hexane/EtOAc 50:50) $R_{\mathrm{f}}=0.30$; $[\alpha]_{\mathrm{D}}^{22}$ $-0.116\left(c=2.17, \mathrm{CHCl}_{3}\right)$; IR (thin film) $\nu_{\max }: 3387$ (br), 3087, 2981, 2937, 1716, 1664, 1597, 1556, 1454, 1374, 1276, 1211, 1156, 1065, 1039, 916, 856, 807, 786, 733, $698 \mathrm{~cm}^{-1}$; ${ }^{1} \mathrm{H}$ NMR $\left(400 \mathrm{MHz}, \mathrm{CDCl}_{3}\right) \delta: 7.53$ (ddd, $\left.J=20.4,8.5,0.7 \mathrm{~Hz}, 1 \mathrm{H}\right)$, 7.35-7.27 (m, 4H), 7.24-7.15 (m, 4H), $6.85(\mathrm{~d}, J=5.1 \mathrm{~Hz}, 2 \mathrm{H})$, $6.51(\mathrm{~d}, J=5.4 \mathrm{~Hz}, 1 \mathrm{H}), 5.68(\mathrm{dd}, J=8.1,4.1 \mathrm{~Hz}, 1 \mathrm{H}), 5.60-5.50$ $(\mathrm{m}, 3 \mathrm{H}), 4.89-4.78(\mathrm{~m}, 2 \mathrm{H}), 4.57(\mathrm{ddt} J=12.0,4.3,2.0 \mathrm{~Hz}$, $1 \mathrm{H}), 4.24(\mathrm{dd}, J=4.4,3.1 \mathrm{~Hz}, 1 \mathrm{H}), 3.78(\mathrm{~d}, J=3.3 \mathrm{~Hz}, 3 \mathrm{H}), 2.83$ $(\mathrm{t}, J=7.5 \mathrm{~Hz}, 2 \mathrm{H}), 2.53(\mathrm{td}, J=7.4,2.0 \mathrm{~Hz}, 2 \mathrm{H}), 1.57(\mathrm{~s}, 3 \mathrm{H})$, $1.36(\mathrm{~s}, 3 \mathrm{H}) ;{ }^{13} \mathrm{C} \mathrm{NMR}\left(101 \mathrm{MHz}, \mathrm{CDCl}_{3}\right) \delta: 162.11,162.08$, $159.50,150.87,150.85,141.07,140.84,140.30,140.27,136.90$, $135.36,135.29,133.99,133.95,133.79,133.64,131.21,129.37$, 129.34, 128.41, 128.39, 126.40, 126.21, 126.18, 125.49, 125.44, $115.34,115.32,114.28,114.24,101.79,101.74,96.69,96.37$, $89.23,89.19,86.83,86.73,84.09,83.93,80.91,69.46,63.02$, $62.99,55.68,34.72,34.70,27.16,25.29,20.87,20.85$; HRMS $\left(\mathrm{ESI}^{+}\right) \mathrm{m} / z$ : calcd for $\mathrm{C}_{37} \mathrm{H}_{34} \mathrm{~N}_{2} \mathrm{O}_{8} \mathrm{NaCl}_{4}[\mathrm{M}+\mathrm{Na}]$, 797.0967; found, 797.0994.

Ribosylation of 14. To a stirred suspension of $14(227 \mathrm{mg}$, $0.292 \mathrm{mmol}), 15$ (497 mg, $0.584 \mathrm{mmol}), \mathrm{MS} 3 \AA$ (900 mg), and $\mathrm{SrCO}_{3}(431 \mathrm{mg}, 2.920 \mathrm{mmol})$ in $\mathrm{CH}_{2} \mathrm{Cl}_{2}(12.0 \mathrm{~mL})$ were added $\mathrm{AgBF}_{4}(28.5 \mathrm{mg}, 0.146 \mathrm{mmol})$ and NIS $(131 \mathrm{mg}, 0.584 \mathrm{mmol})$ at $0{ }^{\circ} \mathrm{C}$. After $24 \mathrm{~h}$, the reaction mixture was added to $\mathrm{Et}_{3} \mathrm{~N}(2 \mathrm{~mL})$ and passed through a silica gel pad (hexane/EtOAc 1:1). The combined organic phase was concentrated in vacuo. The crude mixture was purified by silica gel column chromatography (hexane/EtOAc 90:10 to 80:20 to 70:30) to afford 16 (416 mg, $0.277 \mathrm{mmol}, 95 \%)$ : TLC (hexane/EtOAc 67:33) $R_{\mathrm{f}}=0.70 ;[\alpha]_{\mathrm{D}}^{21}$ $+0.100\left(c=2.09, \mathrm{CHCl}_{3}\right)$; IR (thin film) $\nu_{\max }: 2942,2892,2866$, 2102, 1743, 1724, 1675, 1600, 1556, 1456, 1382, 1371, 1278, 1218, 1099, 1070, 1049, 1013, 999, 882, 807, 772, 745, $681 \mathrm{~cm}^{-1}$; ${ }^{1} \mathrm{H}$ NMR $\left(400 \mathrm{MHz}, \mathrm{CDCl}_{3}\right) \delta: 7.54(\mathrm{dd}, J=23.1,8.5 \mathrm{~Hz}, 1 \mathrm{H})$, $7.32-7.27(\mathrm{~m}, 4 \mathrm{H}), 7.24-7.16(\mathrm{~m}, 4 \mathrm{H}), 6.84(\mathrm{~d}, J=7.3 \mathrm{~Hz}, 2 \mathrm{H})$, $6.51(\mathrm{~d}, J=3.7 \mathrm{~Hz}, 1 \mathrm{H}), 5.71-5.64(\mathrm{~m}, 2 \mathrm{H}), 5.60-5.49(\mathrm{~m}, 2 \mathrm{H})$, $5.20-5.16(\mathrm{~m}, 3 \mathrm{H}), 4.79(\mathrm{ddd}, J=7.5,6.5,3.1 \mathrm{~Hz}, 1 \mathrm{H}), 4.64(\mathrm{td}$, $J=5.9,2.6 \mathrm{~Hz}, 1 \mathrm{H}), 4.57(\mathrm{ddt}, J=11.4,6.3,1.9 \mathrm{~Hz}, 1 \mathrm{H}), 4.28(\mathrm{dt}$, $J=6.2,2.8 \mathrm{~Hz}, 1 \mathrm{H}), 4.19(\mathrm{tt}, J=6.1,3.0 \mathrm{~Hz}, 1 \mathrm{H}), 3.79-3.72(\mathrm{~m}$, $7 \mathrm{H}), 3.50$ (ddd, $J=13.0,7.6,3.3 \mathrm{~Hz}, 1 \mathrm{H}), 3.35$ (dd, $J=13.0,3.4$ $\mathrm{Hz}, 1 \mathrm{H}), 2.83(\mathrm{t}, J=7.4 \mathrm{~Hz}, 2 \mathrm{H}), 2.55(\mathrm{td}, J=7.4,1.8 \mathrm{~Hz}, 2 \mathrm{H})$, $2.29(\mathrm{t}, J=1.6 \mathrm{~Hz}, 2 \mathrm{H}), 2.24(\mathrm{dd}, J=5.1,2.1 \mathrm{~Hz}, 2 \mathrm{H}), 1.62-1.55$ $(\mathrm{m}, 7 \mathrm{H}), 1.36(\mathrm{~d}, J=2.0 \mathrm{~Hz}, 3 \mathrm{H}), 1.08-1.00(\mathrm{~m}, 54 \mathrm{H}) ;{ }^{13} \mathrm{C}$ NMR (101 MHz, $\left.\mathrm{CDCl}_{3}\right) \delta: 175.61,170.98,170.88,170.71$, $170.70,170.64,162.17,162.14,159.45,150.75,150.72,140.39$, $140.19,140.15,140.13,136.92,136.91,135.43,135.29,133.94$, $133.80,133.65,131.24,129.36,129.31,128.46(2 \mathrm{C}), 128.40$ (2C), 126.46, 126.44, 126.19, 126.10, 125.56, 125.45, 115.29, 115.25, 114.23, 114.22, 104.61, 104.55, 101.83, 101.82, 88.84, $88.20,84.44,84.35,83.93,81.43,81.33,80.57,79.88,76.49$, $75.86,75.83,74.12,71.78,71.73,71.40,70.73,69.60,69.47$, $68.85,68.78,59.97,59.96,55.67,46.15,45.97,44.72,44.58$, $34.65,34.51,34.49,32.67,32.61,32.57,28.00,27.38,27.35$, 27.30, 27.07, 25.34, 25.27, 20.89, 18.05 (12C), 11.91 (6C); 
HRMS $\left(\mathrm{ESI}^{+}\right) \mathrm{m} / z$ : calcd for $\mathrm{C}_{74} \mathrm{H}_{106} \mathrm{Cl}_{4} \mathrm{~N}_{5} \mathrm{O}_{15} \mathrm{Si}_{2}[\mathrm{M}+\mathrm{H}]$, 1500.5978; found, 1500.5992 .

Synthesis of 17. A suspension of $16(286 \mathrm{mg}, 0.19 \mathrm{mmol})$, $\mathrm{NH}_{4} \mathrm{Cl}(305 \mathrm{mg}, 5.70 \mathrm{mmol})$, and $\mathrm{Zn}(373 \mathrm{mg}, 5.70 \mathrm{mmol})$ in $\mathrm{EtOH} / \mathrm{H}_{2} \mathrm{O}(9: 1,9.5 \mathrm{~mL})$ was stirred at $80{ }^{\circ} \mathrm{C}$ for $12 \mathrm{~h}$ and cooled to $\mathrm{rt}$. The precipitates were filtered, and the combined organic solution was concentrated in vacuo. The crude mixture was used for the next reaction without purification. To a stirred solution of the crude amide in THF $(9.5 \mathrm{~mL})$ were added saturated aq $\mathrm{NaHCO}_{3}(9.5 \mathrm{~mL})$ and $\mathrm{Boc}_{2} \mathrm{O}(124 \mathrm{mg}, 0.57$ $\mathrm{mmol}$ ). The reaction mixture was stirred for $6 \mathrm{~h}$ at $\mathrm{rt}$, and the aqueous layer was extracted with EtOAc. The combined organic extracts were dried over $\mathrm{Na}_{2} \mathrm{SO}_{4}$ and concentrated in vacuo. The crude mixture was purified by silica gel column chromatography (hexane/EtOAc 85:15 to 80:20 to 67:33) to afford $17(258 \mathrm{mg}$, $0.16 \mathrm{mmol}, 86 \%$ for 2 steps): TLC (hexane $/$ EtOAc $70: 30) R_{\mathrm{f}}=$ 0.30; $[\alpha]_{\mathrm{D}}^{21}+0.012\left(c=0.90, \mathrm{CHCl}_{3}\right)$; IR (thin film) $\nu_{\max }: 3387$ (br), 3090, 2941, 2866, 1742, 1720, 1676, 1600, 1556, 1505, $1456,1366,1278,1219,1161,1100,1070,1049,1013,998,882$, 806, 772, 745, $681 \mathrm{~cm}^{-1} ;{ }^{1} \mathrm{H}$ NMR $\left(400 \mathrm{MHz}, \mathrm{CDCl}_{3}\right) \delta: 7.54$ (dd, $J=19.9,8.5 \mathrm{~Hz}, 1 \mathrm{H}), 7.33-7.27(\mathrm{~m}, 4 \mathrm{H}), 7.24-7.16(\mathrm{~m}$, $4 \mathrm{H}), 6.85(\mathrm{~d}, J=7.3 \mathrm{~Hz}, 2 \mathrm{H}), 6.51(\mathrm{~d}, J=4.8 \mathrm{~Hz}, 1 \mathrm{H}), 5.72-5.64$ $(\mathrm{m}, 2 \mathrm{H}), 5.60-5.48(\mathrm{~m}, 2 \mathrm{H}), 5.26(\mathrm{~d}, J=6.0 \mathrm{~Hz}, 1 \mathrm{H}), 5.17(\mathrm{~d}, J=$ $8.6 \mathrm{~Hz}, 2 \mathrm{H}), 5.13-5.08(\mathrm{~m}, 1 \mathrm{H}), 4.82-4.76(\mathrm{~m}, 1 \mathrm{H}), 4.65(\mathrm{t}, J=$ $7.0 \mathrm{~Hz}, 1 \mathrm{H}), 4.51(\mathrm{dd}, J=13.8,6.0 \mathrm{~Hz}, 1 \mathrm{H}), 4.31-4.26(\mathrm{~m}, 1 \mathrm{H})$, $4.23-4.17(\mathrm{~m}, 1 \mathrm{H}), 3.78(\mathrm{~d}, J=2.7 \mathrm{~Hz}, 3 \mathrm{H}), 3.74(\mathrm{~d}, J=6.9 \mathrm{~Hz}$, $4 \mathrm{H}), 3.48-3.40(\mathrm{~m}, 1 \mathrm{H}), 3.36-3.26(\mathrm{~m}, 1 \mathrm{H}), 2.83(\mathrm{t}, J=7.4 \mathrm{~Hz}$, $2 \mathrm{H}), 2.56(\mathrm{t}, J=7.5 \mathrm{~Hz}, 2 \mathrm{H}), 2.27(\mathrm{t}, J=2.6 \mathrm{~Hz}, 2 \mathrm{H}), 2.23(\mathrm{t}, J=$ $3.0 \mathrm{~Hz}, 2 \mathrm{H}), 1.62-1.55(\mathrm{~m}, 7 \mathrm{H}), 1.42(\mathrm{~s}, 9 \mathrm{H}), 1.37(\mathrm{~d}, J=2.6 \mathrm{~Hz}$, 3H), 1.11-0.99 (m, 54H); ${ }^{13} \mathrm{C}$ NMR $\left(101 \mathrm{MHz}, \mathrm{CDCl}_{3}\right) \delta$ : $159.46,150.79,136.91,131.26,129.33,128.48$ (2C), 128.37 (2C), 126.48, 126.11, 125.44, 115.30, 115.26, 79.95, 59.98, 55.68, $46.42,46.16,45.95,44.83,44.78,42.49,34.51,34.49,32.60$, $32.55,31.91,29.69,28.71,28.40,28.34,27.37,27.33,27.29$, 27.26, 27.09, 27.05, 25.36, 22.68, 22.63, 20.87, 18.06 (6C), 17.90 (6C), 14.12, 11.92 (3C), 11.78 (3C); HRMS (ESI $\left.{ }^{+}\right) m / z$ : calcd for $\mathrm{C}_{79} \mathrm{H}_{116} \mathrm{Cl}_{4} \mathrm{~N}_{3} \mathrm{O}_{17} \mathrm{Si}_{2}[\mathrm{M}+\mathrm{H}], 1574.6597$; found, 1574.6609 .

Synthesis of 21S. To a stirred solution of $17(258 \mathrm{mg}, 0.16$ $\mathrm{mmol})$ and quinoline $(38.7 \mu \mathrm{L}, 0.33 \mathrm{mmol})$ in EtOAc $(50 \mathrm{~mL})$ and $\mathrm{MeOH}(50 \mathrm{~mL})$ was added Lindlar catalyst $(300 \mathrm{mg}) \cdot \mathrm{H}_{2}$ gas was introduced, and the reaction mixture was stirred under a $\mathrm{H}_{2}$ atmosphere $(600 \mathrm{psi})$ at $\mathrm{rt}$. The reaction mixture was stirred for $11 \mathrm{~h}$ under $\mathrm{a}_{2}$ atmosphere $(600 \mathrm{psi})$ at rt. The reaction mixture was filtered through Celite, and the filtrate was washed with $1 \mathrm{~N}$ $\mathrm{HCl}$. The combined organic solution was dried over $\mathrm{Na}_{2} \mathrm{SO}_{4}$ and concentrated in vacuo. The crude mixture was used for the next reaction without purification. To a stirred solution of the crude mixture in $t-\mathrm{BuOH} /$ acetone $(1: 1,2.1 \mathrm{~mL})$ were added NMO $(192 \mathrm{mg}, 1.64 \mathrm{mmol})$ and $\mathrm{OsO}_{4}(4 \%$ in water, $1.04 \mathrm{~mL}, 0.16$ $\mathrm{mmol})$ at rt. After $2 \mathrm{~h}$, the reaction solution was diluted with EtOAc and quenched with saturated aq $\mathrm{NaHCO}_{3} /$ saturated aq $\mathrm{Na}_{2} \mathrm{SO}_{3}(2: 1)$. The heterogeneous mixture was stirred for $30 \mathrm{~min}$ and extracted with EtOAc. The combined organic extracts were dried over $\mathrm{Na}_{2} \mathrm{SO}_{4}$ and concentrated in vacuo. The crude mixture was passed through a silica gel pad (hexane/EtOAc 33:67) to afford the diols as a diastereomeric mixture. This mixture was used for the next reaction without further purification. To a stirred solution of the diols $(22.1 \mathrm{mg}, 0.014 \mathrm{mmol})$ and $\mathrm{NaHCO}_{3}$ (11.5 mg, $0.14 \mathrm{mmol})$ in $\mathrm{CH}_{2} \mathrm{Cl}_{2}(0.7 \mathrm{~mL})$ was added $\mathrm{Pb}(\mathrm{OAc})_{4}$ (12.1 mg, $0.027 \mathrm{mmol}$ ) at $0{ }^{\circ} \mathrm{C}$. The reaction mixture was stirred for $2 \mathrm{~h}$ at $0{ }^{\circ} \mathrm{C}$, quenched with saturated aq $\mathrm{NaHCO}_{3}$, and extracted with EtOAc. The combined organic extracts were dried over $\mathrm{Na}_{2} \mathrm{SO}_{4}$ and concentrated in vacuo. The crude aldehyde $\mathbf{1 8}$ was used for the next reaction without purification. To a stirred solution of $(\mathrm{BnO})_{2} \mathrm{P}(\mathrm{O})-\mathrm{CH}_{2}-\mathrm{P}(\mathrm{O})(\mathrm{OBn}) \mathrm{OH}(30.6 \mathrm{mg}$, $0.069 \mathrm{mmol})$ in $\mathrm{CH}_{2} \mathrm{Cl}_{2}(0.4 \mathrm{~mL})$ was added a $\mathrm{CH}_{2} \mathrm{Cl}_{2}(0.3$ $\mathrm{mL})$ solution of 18 and 19. To the reaction mixture was added TMSCN $(17.1 \mu \mathrm{L}, 0.14 \mathrm{mmol})$ and stirred for $9 \mathrm{~h}$ at $\mathrm{rt}$. After completion, the reaction mixture was quenched with saturated aq $\mathrm{NaHCO}_{3}$ and extracted with EtOAc. The combined organic extracts were dried over $\mathrm{Na}_{2} \mathrm{SO}_{4}$ and concentrated in vacuo. The crude product was purified by silica gel column chromatography (hexane/EtOAc 80:20 to 60:40) to afford the Strecker products. To a stirred solution of the desired Strecker product $(8.8 \mathrm{mg}, 5.0$ $\mu \mathrm{mol})$ in $\mathrm{EtOH} / \mathrm{H}_{2} \mathrm{O}(9: 1,0.5 \mathrm{~mL})$ were added $\mathrm{HgCl}_{2}(2.7 \mathrm{mg}$, $0.010 \mathrm{mmol})$ and acetaldoxime $(3.0 \mu \mathrm{L}, 0.050 \mathrm{mmol})$ at $\mathrm{rt}$. After being stirred for $6 \mathrm{~h}$ at $\mathrm{rt}$, the reaction mixture was concentrated under reduced pressure. The residue was quenched with saturated aq $\mathrm{NaHCO}_{3}$ and extracted with $\mathrm{CHCl}_{3}$. The combined organic extracts were dried over $\mathrm{Na}_{2} \mathrm{SO}_{4}$ and concentrated in vacuo. The crude product was purified by silica gel column chromatography (hexane/EtOAc 80:20 to 60:40) to afford $21 \mathrm{~S}$ (16.7 mg, $9.49 \mu \mathrm{mol}, 69 \%$ for two steps) and $21 R$ (4.1 mg, 2.34 $\mu$ mol, $17 \%$ for two steps): $21 S$ : TLC (hexane/EtOAc 60:40) $R_{\mathrm{f}}=$ 0.40; $[\alpha]_{\mathrm{D}}^{21}+0.075\left(c=0.73, \mathrm{CHCl}_{3}\right)$; IR (thin film) $\nu_{\max }: 3317$ (br), 2930, 2865, 1719, 1675, 1600, 1462, 1102, 1071, 882, 772, $683 \mathrm{~cm}^{-1} ;{ }^{1} \mathrm{H}$ NMR (400 MHz, $\mathrm{CDCl}_{3}$ ) $\delta: 7.68(\mathrm{~s}, 1 \mathrm{H}), 7.49$ (dd, $J=11.4,8.8 \mathrm{~Hz}, 1 \mathrm{H}), 7.39(\mathrm{~d}, J=7.9 \mathrm{~Hz}, 2 \mathrm{H}), 7.32(\mathrm{~s}, 1 \mathrm{H})$, $7.19(\mathrm{~d}, J=8.5 \mathrm{~Hz}, 2 \mathrm{H}), 7.11(\mathrm{~d}, J=8.0 \mathrm{~Hz}, 2 \mathrm{H}), 6.86(\mathrm{~d}, J=9.3$ $\mathrm{Hz}, 2 \mathrm{H}), 6.50(\mathrm{~d}, J=15.4 \mathrm{~Hz}, 1 \mathrm{H}), 5.73(\mathrm{dd}, J=23.0,8.0 \mathrm{~Hz}$, $1 \mathrm{H}), 5.59(\mathrm{~d}, J=5.9 \mathrm{~Hz}, 1 \mathrm{H}), 5.54(\mathrm{~d}, J=9.4 \mathrm{~Hz}, 2 \mathrm{H}), 5.42(\mathrm{t}, J=$ $10.1 \mathrm{~Hz}, 1 \mathrm{H}), 5.25(\mathrm{~s}, 1 \mathrm{H}), 5.08-5.00(\mathrm{~m}, 2 \mathrm{H}), 4.96-4.82(\mathrm{~m}$, $2 \mathrm{H}), 4.50-4.45(\mathrm{~m}, 1 \mathrm{H}), 4.25-4.19(\mathrm{~m}, 1 \mathrm{H}), 4.15-4.06(\mathrm{~m}$, $1 \mathrm{H}), 3.94-3.83(\mathrm{~m}, 1 \mathrm{H}), 3.80-3.63(\mathrm{~m}, 10 \mathrm{H}), 3.49-3.41(\mathrm{~m}$, $1 \mathrm{H}), 3.39-3.31(\mathrm{~m}, 1 \mathrm{H}), 3.03(\mathrm{dt}, J=12.0,6.1 \mathrm{~Hz}, 1 \mathrm{H}), 2.71-$ $2.61(\mathrm{~m}, 1 \mathrm{H}), 2.54(\mathrm{t}, J=7.3 \mathrm{~Hz}, 2 \mathrm{H}), 2.51-2.45(\mathrm{~m}, 1 \mathrm{H}), 2.29-$ $2.17(\mathrm{~m}, 4 \mathrm{H}), 1.67-1.51(\mathrm{~m}, 10 \mathrm{H}), 1.41(\mathrm{~s}, 9 \mathrm{H}), 1.28(\mathrm{dd}, J=$ 15.7, 8.1 Hz, 10H), $1.05(\mathrm{~s}, 42 \mathrm{H}), 1.01(\mathrm{~s}, 6 \mathrm{H}), 0.95(\mathrm{~s}, 6 \mathrm{H}), 0.87$ $(\mathrm{t}, J=6.4 \mathrm{~Hz}, 3 \mathrm{H}) ;{ }^{13} \mathrm{C} \mathrm{NMR}\left(101 \mathrm{MHz}, \mathrm{CDCl}_{3}\right) \delta: 170.9,159.5$, $136.9,136.8,131.3,131.2,129.42,129.36,128.84$ (2C), 128.82 (2C), 128.80 (2C), 126.4, 126.2, 125.1, 120.09, 120.05, 115.4, $115.31,115.30,114.84,114.81,84.90,84.87,80.84,80.78,80.2$, 79.8, 79.4, 78.2, 76.1, 74.3, 60.0, 59.9, 55.8, 55.7, 52.0, 46.2, 46.0, $44.83,44.77,35.4,32.56,32.55,31.8,31.5,29.7,29.19,29.16$, 28.4, 28.3, 27.3, 27.2, 22.7, 18.1 (12C), 14.1, 11.9 (6C); HRMS $\left(\mathrm{ESI}^{+}\right) \mathrm{m} / z$ : calcd for $\mathrm{C}_{88} \mathrm{H}_{135} \mathrm{Cl}_{4} \mathrm{~N}_{6} \mathrm{O}_{18} \mathrm{Si}_{2}[\mathrm{M}+\mathrm{H}], 1759.8126$; found, 1759.8135 .

21R. TLC (hexane/EtOAc 60:40) $R_{\mathrm{f}}=0.30 ;{ }^{1} \mathrm{H}$ NMR (400 $\left.\mathrm{MHz}, \mathrm{CDCl}_{3}\right) \delta: 7.74(\mathrm{dd} J=16.8,11.4 \mathrm{~Hz}, 1 \mathrm{H}), 7.51(\mathrm{dd}, J=$ $11.7,8.5 \mathrm{~Hz}, 1 \mathrm{H}), 7.47-7.29(\mathrm{~m}, 3 \mathrm{H}), 7.23-7.15(\mathrm{~m}, 2 \mathrm{H}), 7.10$ $(\mathrm{t}, J=9.5 \mathrm{~Hz}, 2 \mathrm{H}), 6.85(\mathrm{~d}, J=8.8 \mathrm{~Hz}, 2 \mathrm{H}), 6.49(\mathrm{~d}, J=4.6 \mathrm{~Hz}$, $1 \mathrm{H}), 5.76(\mathrm{dd}, J=21.1,8.1 \mathrm{~Hz}, 1 \mathrm{H}), 5.65(\mathrm{~d}, J=23.4 \mathrm{~Hz}, 1 \mathrm{H})$, $5.56(\mathrm{~d}, J=9.2 \mathrm{~Hz}, 1 \mathrm{H}), 5.52(\mathrm{~d}, J=3.9 \mathrm{~Hz}, 1 \mathrm{H}), 5.46(\mathrm{t}, J=10.8$ $\mathrm{Hz}, 1 \mathrm{H}), 5.40-5.23(\mathrm{~m}, 2 \mathrm{H}), 5.23-5.16(\mathrm{~m}, 1 \mathrm{H}), 5.10-5.05(\mathrm{~m}$, $1 \mathrm{H}), 5.02(\mathrm{~s}, 1 \mathrm{H}), 4.90-4.78(\mathrm{~m}, 1 \mathrm{H}), 4.26(\mathrm{t}, J=6.3 \mathrm{~Hz}, 1 \mathrm{H})$, $4.21(\mathrm{~d}, J=8.9 \mathrm{~Hz}, 1 \mathrm{H}), 3.96-3.89(\mathrm{~m}, 1 \mathrm{H}), 3.80-3.71(\mathrm{~m}$, $10 \mathrm{H}), 3.68-3.63(\mathrm{~m}, 1 \mathrm{H}), 3.48-3.39(\mathrm{~m}, 1 \mathrm{H}), 3.04-2.95(\mathrm{~m}$, $1 \mathrm{H}), 2.75-2.66(\mathrm{~m}, 1 \mathrm{H}), 2.53(\mathrm{t}, J=7.7 \mathrm{~Hz}, 2 \mathrm{H}), 2.44(\mathrm{~d}, J=$ $12.1 \mathrm{~Hz}, 1 \mathrm{H}), 2.37-2.27(\mathrm{~m}, 2 \mathrm{H}), 2.23(\mathrm{~d}, J=14.7 \mathrm{~Hz}, 2 \mathrm{H})$, $1.65-1.51(\mathrm{~m}, 10 \mathrm{H}), 1.42(\mathrm{~s}, 9 \mathrm{H}), 1.36-1.23(\mathrm{~m}, 10 \mathrm{H}), 1.08-$ $1.01(\mathrm{~m}, 42 \mathrm{H}), 0.97(\mathrm{~s}, 6 \mathrm{H}), 0.90-0.85(\mathrm{~m}, 9 \mathrm{H})$; HRMS $\left(\mathrm{ESI}^{+}\right)$ $m / z$ : calcd for $\mathrm{C}_{88} \mathrm{H}_{135} \mathrm{Cl}_{4} \mathrm{~N}_{6} \mathrm{O}_{18} \mathrm{Si}_{2}[\mathrm{M}+\mathrm{H}], 1759.8126$; found, 1759.8113

Synthesis of 22. To a stirred solution of $21 S(8.8 \mathrm{mg}, 5.0$ $\mu \mathrm{mol})$ in $\mathrm{EtOH} / \mathrm{H}_{2} \mathrm{O}(9: 1,0.5 \mathrm{~mL})$ were added $\mathrm{HgCl}_{2}(2.7 \mathrm{mg}$, $0.010 \mathrm{mmol})$ and acetaldoxime $(3.0 \mu \mathrm{L}, 0.050 \mathrm{mmol})$ at rt. After 
being stirred for $6 \mathrm{~h}$ at $\mathrm{rt}$, the reaction mixture was concentrated under reduced pressure. The residue was quenched with saturated aq $\mathrm{NaHCO}_{3}$ and extracted with $\mathrm{CHCl}_{3}$. The combined organic extracts were dried over $\mathrm{Na}_{2} \mathrm{SO}_{4}$ and concentrated in vacuo. The crude product was purified by silica gel column chromatography $\left(\mathrm{CHCl}_{3} / \mathrm{MeOH} 99.5: 0.5\right.$ to $99.2: 0.8$ to 98.8:1.2) to afford $22(7.9 \mathrm{mg}, 4.5 \mu \mathrm{mol}, 89 \%)$ : TLC $\left(\mathrm{CHCl}_{3} /\right.$ MeOH 95:5) $R_{\mathrm{f}}=0.40$; IR (thin film) $\nu_{\text {max }}: 3335$ (br), 2927, 2865, 1668, 1601, 1460, 1099, 1071, 882, $681 \mathrm{~cm}^{-1}$; ${ }^{1} \mathrm{H}$ NMR $\left(400 \mathrm{MHz}, \mathrm{CDCl}_{3}\right) \delta: 7.59(\mathrm{dd}, J=19.5,8.5 \mathrm{~Hz}, 1 \mathrm{H}), 7.40(\mathrm{~d}, J=$ $8.0 \mathrm{~Hz}, 2 \mathrm{H}), 7.30(\mathrm{t}, J=2.6 \mathrm{~Hz}, 1 \mathrm{H}), 7.24-7.18(\mathrm{~m}, 1 \mathrm{H}), 7.11(\mathrm{~d}$, $J=8.0 \mathrm{~Hz}, 2 \mathrm{H}), 6.84(\mathrm{~d}, J=7.2 \mathrm{~Hz}, 2 \mathrm{H}), 6.50(\mathrm{~s}, 1 \mathrm{H}), 5.84(\mathrm{br} \mathrm{s}$, $1 \mathrm{H}), 5.59-5.47(\mathrm{~m}, 3 \mathrm{H}), 5.26-5.14(\mathrm{~m}, 2 \mathrm{H}), 5.06-4.97(\mathrm{~m}$, $1 \mathrm{H}), 4.96-4.87(\mathrm{~m}, 1 \mathrm{H}), 4.84-4.73(\mathrm{~m}, 1 \mathrm{H}), 4.55(\mathrm{t}, J=5.0 \mathrm{~Hz}$, $1 \mathrm{H}), 4.28-4.14(\mathrm{~m}, 2 \mathrm{H}), 3.80-3.70(\mathrm{~m}, 7 \mathrm{H}), 3.59-3.46(\mathrm{~m}$, $1 \mathrm{H}), 3.41$ (brs, $2 \mathrm{H}), 2.83$ (brs, $2 \mathrm{H}), 2.54(\mathrm{t}, J=7.7 \mathrm{~Hz}, 3 \mathrm{H})$, $2.50-2.43(\mathrm{~m}, 1 \mathrm{H}), 2.29-2.21(\mathrm{~m}, 4 \mathrm{H}), 1.99$ (brs, $2 \mathrm{H}), 1.65-$ $1.53(\mathrm{~m}, 10 \mathrm{H}), 1.43(\mathrm{~s}, 9 \mathrm{H}), 1.35(\mathrm{~d}, J=5.2 \mathrm{~Hz}, 3 \mathrm{H}), 1.32-1.24$ $(\mathrm{m}, 10 \mathrm{H}), 1.05(\mathrm{~d}, J=3.2 \mathrm{~Hz}, 48 \mathrm{H}), 1.00-0.97(\mathrm{~m}, 6 \mathrm{H}), 0.87(\mathrm{t}$, $J=6.8 \mathrm{~Hz}, 3 \mathrm{H}) ;{ }^{13} \mathrm{C} \mathrm{NMR}\left(101 \mathrm{MHz}, \mathrm{CDCl}_{3}\right) \delta: 159.6,159.5$, $136.87,136.85,136.4,135.2,134.0,133.64,133.59,131.3$, $129.42,129.40,128.9$ (2C), 126.2, 125.3, 120.2, 120.1, 115.4 (2C), 74.5, 60.0, 59.9, 55.73, 55.72, 46.2, 46.1, 46.0, 44.8, 35.4, 32.7, 32.6, 31.8, 31.5, 29.69, 29.67, 29.6, 29.5, 29.4, 29.3, 29.24, $29.16,29.09,28.51,28.49,28.48,28.45,28.43,28.42,28.36$, $28.33,28.31,28.28,27.33,27.30,27.25,27.2,25.3,22.7,18.1$ (12C), 14.1, 11.9 (6C); HRMS (ESI $\left.{ }^{+}\right) \mathrm{m} / z$ : calcd for $\mathrm{C}_{88} \mathrm{H}_{137} \mathrm{Cl}_{4} \mathrm{~N}_{6} \mathrm{O}_{19} \mathrm{Si}_{2}[\mathrm{M}+\mathrm{H}], 1777.8231$; found, 1777.8219 .

Synthesis of 23. To a stirred solution of $22(5.8 \mathrm{mg}, 3.3 \mu \mathrm{mol})$ and paraformaldehyde $(2.9 \mathrm{mg}, 0.098 \mathrm{mmol})$ in $\mathrm{CH}_{3} \mathrm{CN}(0.5$ $\mathrm{mL}$ ) was added $\mathrm{NaB}(\mathrm{CN}) \mathrm{H}_{3}(6.2 \mathrm{mg}, 0.098 \mathrm{mmol})$. After being stirred for $4 \mathrm{~h}$ at $\mathrm{rt}$, the reaction mixture was quenched with saturated aq $\mathrm{NaHCO}_{3}$ and extracted with $\mathrm{CHCl}_{3}$. The combined organic extracts were dried over $\mathrm{Na}_{2} \mathrm{SO}_{4}$ and concentrated in vacuo. The crude product was purified by silica gel column chromatography (hexane/EtOAc 40:60) to afford 23 (5.5 mg, $3.1 \mu \mathrm{mol}, 95 \%):$ TLC (hexane/EtOAc 33:67) $R_{\mathrm{f}}=0.60 ;[\alpha]_{\mathrm{D}}^{21}$ $+0.022\left(c=0.28, \mathrm{CHCl}_{3}\right)$; IR (thin film) $\nu_{\max }: 2932,2866,1718$, 1672, 1601, 1463, 1101, 1071, $884 \mathrm{~cm}^{-1}$; ${ }^{1} \mathrm{H}$ NMR (400 MHz, $\left.\mathrm{CDCl}_{3}\right) \delta: 7.75(\mathrm{~d}, J=17.0 \mathrm{~Hz}, 1 \mathrm{H}), 7.56(\mathrm{~d}, J=8.6 \mathrm{~Hz}, 1 \mathrm{H})$, $7.43(\mathrm{~d}, J=8.1 \mathrm{~Hz}, 2 \mathrm{H}), 7.34(\mathrm{~d}, J=8.1 \mathrm{~Hz}, 1 \mathrm{H}), 7.30(\mathrm{~s}, 2 \mathrm{H})$, $7.20(\mathrm{dt}, J=8.5,2.0 \mathrm{~Hz}, 1 \mathrm{H}), 7.10(\mathrm{~d}, J=8.1 \mathrm{~Hz}, 2 \mathrm{H}), 6.85(\mathrm{~s}$, $2 \mathrm{H}), 6.51(\mathrm{~d}, J=7.9 \mathrm{~Hz}, 1 \mathrm{H}), 6.28(\mathrm{brs}, 1 \mathrm{H}), 5.95(\mathrm{~d}, J=21.6 \mathrm{~Hz}$, $1 \mathrm{H}), 5.84-5.78(\mathrm{~m}, 1 \mathrm{H}), 5.74(\mathrm{~d}, J=23.3 \mathrm{~Hz}, 1 \mathrm{H}), 5.54(\mathrm{~s}, 2 \mathrm{H})$, 5.49 (d, $J=9.6 \mathrm{~Hz}, 1 \mathrm{H}), 5.18$ (brs, $1 \mathrm{H}), 5.11(\mathrm{~s}, 2 \mathrm{H}), 5.02$ (brs, $1 \mathrm{H}), 4.88-4.83(\mathrm{~m}, 1 \mathrm{H}), 4.80-4.74(\mathrm{~m}, 1 \mathrm{H}), 4.39-4.31(\mathrm{~m}$, $2 \mathrm{H}), 4.24-4.18(\mathrm{~m}, 1 \mathrm{H}), 3.92(\mathrm{t}, J=5.8 \mathrm{~Hz}, 1 \mathrm{H}), 3.78(\mathrm{~s}, 3 \mathrm{H})$, $3.74(\mathrm{q}, J=6.6 \mathrm{~Hz}, 4 \mathrm{H}), 3.68-3.63(\mathrm{~m}, 1 \mathrm{H}), 3.50-3.40(\mathrm{~m}, 2 \mathrm{H})$, 3.37-3.30 (m, 1H), 2.83-2.74 (m, 1H), 2.68-2.59 (m, 1H), $2.54(\mathrm{t}, J=7.8 \mathrm{~Hz}, 2 \mathrm{H}), 2.49(\mathrm{~s}, 3 \mathrm{H}), 2.37(\mathrm{q}, J=8.0,7.6 \mathrm{~Hz}, 2 \mathrm{H})$, $2.29-2.20(\mathrm{~m}, 4 \mathrm{H}), 1.98-1.88(\mathrm{~m}, 2 \mathrm{H}), 1.62-1.52(\mathrm{~m}, 6 \mathrm{H})$, $1.40(\mathrm{~s}, 9 \mathrm{H}), 1.36$ (brs, 3H), 1.33-1.23 (m, 6H), 1.09-1.01 (m, $48 \mathrm{H}), 0.98(\mathrm{~s}, 6 \mathrm{H}), 0.87(\mathrm{t}, J=6.4 \mathrm{~Hz}, 3 \mathrm{H}) ;{ }^{13} \mathrm{C} \mathrm{NMR}(101$ $\left.\mathrm{MHz}, \mathrm{CDCl}_{3}\right) \delta: 171.0,162.0,159.5,157.1,136.9,131.3,129.4$, 128.7 (2C), 119.9 (2C), 115.3, 115.1, 114.2, 70.6, 70.1, 69.9, 67.1, 60.4, 60.1, 59.96, 59.95, 58.9, 55.8, 55.7, 54.4, 54.1, 46.22, 46.16, 46.1, 45.3, 44.9, 44.8, 44.7, 42.3, 41.2, 39.93, 39.86, 39.6, $39.04,38.97,35.4,32.7,32.64,32.63,32.62,32.58,31.9,31.8$, $31.7,31.6,31.53,31.48,29.69,29.67,29.6,29.4,29.22,29.17$, 28.50, 28.49, 28.4, 27.29, 27.28, 27.21, 27.17, 25.23, 25.20, 22.68, 22.66, 18.1 (12C), 14.1, 11.9 (6C); HRMS $\left(\mathrm{ESI}^{+}\right) \mathrm{m} / z$ : calcd for $\mathrm{C}_{89} \mathrm{H}_{139} \mathrm{Cl}_{4} \mathrm{~N}_{6} \mathrm{O}_{19} \mathrm{Si}_{2}[\mathrm{M}+\mathrm{H}], 1791.8388$; found, 1791.8404 .
Synthesis of 24S. To a stirred solution of the diols $(32.5 \mathrm{mg}$, $0.020 \mathrm{mmol}$ ) synthesized for $21 \mathrm{~S}$ and $\mathrm{NaHCO}_{3}(16.9 \mathrm{mg}, 0.20$ $\mathrm{mmol})$ in $\mathrm{CH}_{2} \mathrm{Cl}_{2}(1.0 \mathrm{~mL})$ was added $\mathrm{Pb}(\mathrm{OAc})_{4}(17.9 \mathrm{mg}$, $0.040 \mathrm{mmol}$ ) at $0{ }^{\circ} \mathrm{C}$. The reaction mixture was stirred for $2 \mathrm{~h}$ at 0 ${ }^{\circ} \mathrm{C}$, quenched with saturated aq $\mathrm{NaHCO}_{3}$, and extracted with EtOAc. The combined organic extracts were dried over $\mathrm{Na}_{2} \mathrm{SO}_{4}$ and concentrated in vacuo. The crude aldehyde $\mathbf{1 8}$ was used for the next reaction without purification. To a stirred solution of $(\mathrm{BnO})_{2} \mathrm{P}(\mathrm{O})-\mathrm{CH}_{2}-\mathrm{P}(\mathrm{O})(\mathrm{OBn}) \mathrm{OH}(45.0 \mathrm{mg}, 0.10 \mathrm{mmol})$ in $\mathrm{CH}_{2} \mathrm{Cl}_{2}(0.5 \mathrm{~mL})$ was added a $\mathrm{CH}_{2} \mathrm{Cl}_{2}(0.5 \mathrm{~mL})$ solution of $\mathbf{1 8}$ and 20. After $6 \mathrm{~h}$, to the reaction mixture was added TMSCN $(25.2 \mu \mathrm{L}, 0.20 \mathrm{mmol})$ and stirred for $12 \mathrm{~h}$ at rt. After completion, the reaction mixture was quenched with saturated aq $\mathrm{NaHCO}_{3}$ and extracted with EtOAc. The combined organic extracts were dried over $\mathrm{Na}_{2} \mathrm{SO}_{4}$ and concentrated in vacuo. The crude product was purified by silica gel column chromatography (hexane/EtOAc 80:20 to 60:40) to afford $24 S(23.9 \mathrm{mg}, 12.0$ $\mu \mathrm{mol}, 61 \%$ for two steps) and $24 R(5.1 \mathrm{mg}, 2.6 \mu \mathrm{mol}, 13 \%$ for two steps). 24S: TLC (hexane/EtOAc 50:50) $R_{\mathrm{f}}=0.40 ;[\alpha]_{\mathrm{D}}^{21}$ $+0.102\left(c=0.75, \mathrm{CHCl}_{3}\right)$; IR (thin film) $\nu_{\max }: 3342(\mathrm{br}), 2941$, $2866,1718,1675,1505,1464,1243,1164,1101,1071,883,772$, $688 \mathrm{~cm}^{-1}$; ${ }^{1} \mathrm{H}$ NMR $\left(400 \mathrm{MHz}, \mathrm{CDCl}_{3}\right) \delta: 7.49$ (dd, $J=8.5,4.3$ $\mathrm{Hz}, 1 \mathrm{H}), 7.32(\mathrm{~d}, J=2.0 \mathrm{~Hz}, 1 \mathrm{H}), 7.22-7.11(\mathrm{~m}, 7 \mathrm{H}), 6.94-6.88$ $(\mathrm{m}, 5 \mathrm{H}), 6.86(\mathrm{~d}, J=6.5 \mathrm{~Hz}, 2 \mathrm{H}), 6.50(\mathrm{~d}, J=8.6 \mathrm{~Hz}, 1 \mathrm{H}), 6.25-$ $6.16(\mathrm{~m}, 1 \mathrm{H}), 5.73(\mathrm{dd}, J=22.2,8.0 \mathrm{~Hz}, 1 \mathrm{H}), 5.60(\mathrm{t}, J=8.8 \mathrm{~Hz}$, $1 \mathrm{H}), 5.56-5.41(\mathrm{~m}, 3 \mathrm{H}), 5.21(\mathrm{~d}, J=4.4 \mathrm{~Hz}, 1 \mathrm{H}), 5.05-4.98(\mathrm{~m}$, $2 \mathrm{H}), 4.94-4.77(\mathrm{~m}, 2 \mathrm{H}), 4.53-4.37(\mathrm{~m}, 3 \mathrm{H}), 4.25-4.16(\mathrm{~m}$, $2 \mathrm{H}), 4.05-3.98(\mathrm{~m}, 1 \mathrm{H}), 3.80-3.69(\mathrm{~m}, 6 \mathrm{H}), 3.68-3.63(\mathrm{~m}$, $1 \mathrm{H}), 3.56(\mathrm{dd}, J=17.3,3.4 \mathrm{~Hz}, 1 \mathrm{H}), 3.48(\mathrm{ddt}, J=11.6,7.2,4.0$ $\mathrm{Hz}, 2 \mathrm{H}), 3.44-3.29(\mathrm{~m}, 1 \mathrm{H}), 3.08(\mathrm{dq}, J=9.5,5.3,4.8 \mathrm{~Hz}, 2 \mathrm{H})$, $2.95(\mathrm{dt}, J=11.4,5.5 \mathrm{~Hz}, 1 \mathrm{H}), 2.47(\mathrm{td}, J=12.0,11.4,5.7 \mathrm{~Hz}$, $1 \mathrm{H}), 2.36-2.14(\mathrm{~m}, 5 \mathrm{H}), 2.13-2.05(\mathrm{~m}, 2 \mathrm{H}), 1.97-1.85(\mathrm{~m}$, $3 \mathrm{H}), 1.84-1.75(\mathrm{~m}, 1 \mathrm{H}), 1.58(\mathrm{t}, J=6.9 \mathrm{~Hz}, 2 \mathrm{H}), 1.55-1.50(\mathrm{~m}$, $4 \mathrm{H}), 1.40(\mathrm{~s}, 9 \mathrm{H}), 1.33(\mathrm{~d}, J=4.8 \mathrm{~Hz}, 3 \mathrm{H}), 1.28-1.23(\mathrm{~m}, 3 \mathrm{H})$, $1.08-1.02(\mathrm{~m}, 42 \mathrm{H}), 1.01(\mathrm{~s}, 6 \mathrm{H}), 0.94(\mathrm{~d}, J=2.1 \mathrm{~Hz}, 6 \mathrm{H}) ;{ }^{13} \mathrm{C}$ NMR $\left(101 \mathrm{MHz} \mathrm{CDCl}_{3}\right) \delta: 172.4,171.0,170.9,159.5,155.8$, $150.9,150.7,142.8,136.9,136.8,135.3,135.1,134.13,134.05$, $133.86,133.85,133.78,131.2,131.1,129.42,129.37,129.0$, $126.4,126.2,125.5,125.2,122.5$ (2C), 121.8, 119.3, 118.4, 116.8 (2C), 116.6 (2C), 115.4, 115.3, 114.71, 114.66, 106.4, 102.3, $102.2,84.8,80.7,80.6,79.9,79.8,79.3,76.2,74.32,74.30,72.9$, $60.38,60.35,60.0,59.9,55.72,55.71,52.0,46.6,46.2,45.9,44.84$ $44.77,42.99,42.96,42.4,41.2,33.53,33.49,32.6,32.5,30.3,28.4$, 27.3 (2C), 27.17, 27.16, 27.1, 25.4, 18.1 (12C), 14.2, 14.1, 11.91 (3C), 11.90 (3C); HRMS (ESI $\left.{ }^{+}\right) \mathrm{m} / z$ : calcd for $\mathrm{C}_{94} \mathrm{H}_{135} \mathrm{Cl}_{4} \mathrm{~F}_{3} \mathrm{~N}_{7} \mathrm{O}_{20} \mathrm{Si}_{2}[\mathrm{M}+\mathrm{H}], 1934.8007$; found, 1934.8021 . 24R: TLC (hexane/EtOAc 60:40) $R_{\mathrm{f}}=0.30 ;{ }^{1} \mathrm{H}$ NMR (400 $\mathrm{MHz}$, chloroform- $d) \delta: 7.53(\mathrm{~d}, J=8.7 \mathrm{~Hz}, 1 \mathrm{H}), 7.33-7.29(\mathrm{~m}$, $1 \mathrm{H}), 7.21-7.07(\mathrm{~m}, 7 \mathrm{H}), 6.94-6.88(\mathrm{~m}, 5 \mathrm{H}), 6.85(\mathrm{~d}, J=6.8 \mathrm{~Hz}$ $2 \mathrm{H}), 6.54(\mathrm{~s}, 1 \mathrm{H}), 5.71(\mathrm{~d}, J=7.9 \mathrm{~Hz}, 1 \mathrm{H}), 5.58-5.49(\mathrm{~m}, 3 \mathrm{H})$, $5.46(\mathrm{t}, J=8.9 \mathrm{~Hz}, 1 \mathrm{H}), 5.24-5.20(\mathrm{~m}, 1 \mathrm{H}), 5.15-5.08(\mathrm{~m}, 1 \mathrm{H})$, $5.08-5.00(\mathrm{~m}, 1 \mathrm{H}), 4.92(\mathrm{dd}, J=11.5,5.6 \mathrm{~Hz}, 1 \mathrm{H}), 4.85-4.78$ $(\mathrm{m}, 1 \mathrm{H}), 4.49-4.39(\mathrm{~m}, 2 \mathrm{H}), 4.39-4.18(\mathrm{~m}, 3 \mathrm{H}), 3.98(\mathrm{dd}, J=$ $11.1,5.4 \mathrm{~Hz}, 1 \mathrm{H}), 3.81-3.70(\mathrm{~m}, 6 \mathrm{H}), 3.69-3.61(\mathrm{~m}, 2 \mathrm{H})$, $3.52-3.43(\mathrm{~m}, 2 \mathrm{H}), 3.37-3.32(\mathrm{~m}, 1 \mathrm{H}), 3.08$ (ddd, $J=12.4,8.5$, $3.8 \mathrm{~Hz}, 2 \mathrm{H}), 2.99-2.91(\mathrm{~m}, 1 \mathrm{H}), 2.65(\mathrm{dd}, J=12.8,6.5 \mathrm{~Hz}, 1 \mathrm{H})$, $2.31-2.18(\mathrm{~m}, 5 \mathrm{H}), 2.13-2.04(\mathrm{~m}, 2 \mathrm{H}), 1.96-1.85(\mathrm{~m}, 4 \mathrm{H})$, $1.67-1.52(\mathrm{~m}, 6 \mathrm{H}), 1.40(\mathrm{~s}, 9 \mathrm{H}), 1.38-1.29(\mathrm{~m}, 3 \mathrm{H}), 1.25(\mathrm{~s}$, $6 \mathrm{H}), 1.10-0.98(\mathrm{~m}, 42 \mathrm{H}), 0.97(\mathrm{~s}, 6 \mathrm{H}), 0.88(\mathrm{t}, J=6.7 \mathrm{~Hz}, 3 \mathrm{H})$; HRMS $\left(\mathrm{ESI}^{+}\right) \mathrm{m} / z$ : calcd for $\mathrm{C}_{94} \mathrm{H}_{135} \mathrm{Cl}_{4} \mathrm{~F}_{3} \mathrm{~N}_{7} \mathrm{O}_{20} \mathrm{Si}_{2}[\mathrm{M}+\mathrm{H}]$, 1934.8007; found, 1934.8000 .

Synthesis of 25. To a stirred solution of $24 S(15.4 \mathrm{mg}, 8.0$ $\mu \mathrm{mol})$ in $\mathrm{EtOH} / \mathrm{H}_{2} \mathrm{O}(9: 1,0.5 \mathrm{~mL})$ were added $\mathrm{HgCl}_{2}(4.3 \mathrm{mg}$, 
$0.016 \mathrm{mmol})$ and acetaldoxime $(4.9 \mu \mathrm{L}, 0.080 \mathrm{mmol})$ at rt. After being stirred for $6 \mathrm{~h}$ at $\mathrm{rt}$, the reaction mixture was concentrated under reduced pressure. The residue was quenched with saturated aq $\mathrm{NaHCO}_{3}$ and extracted with $\mathrm{CHCl}_{3}$. The combined organic extracts were dried over $\mathrm{Na}_{2} \mathrm{SO}_{4}$ and concentrated in vacuo. The crude product was purified by silica gel column chromatography $\left(\mathrm{CHCl}_{3} / \mathrm{MeOH} 99.5: 0.5\right.$ to $99.2: 0.8$ to 98.8:1.2) to afford $25(15.3 \mathrm{mg}, 7.8 \mu \mathrm{mol}, 98 \%)$ : TLC $\left(\mathrm{CHCl}_{3} / \mathrm{MeOH}\right.$ 95:5) $R_{\mathrm{f}}=0.30 ;[\alpha]_{\mathrm{D}}^{21}+0.144(c=0.53$, $\mathrm{CHCl}_{3}$ ); IR (thin film) $\nu_{\max }: 3335$ (br), 2940, 2866, 1719, 1676, $1505,1464,1367,1242,1162,1101,1070,882,681 \mathrm{~cm}^{-1} ;{ }^{1} \mathrm{H}$ NMR $\left(400 \mathrm{MHz} \mathrm{CDCl}_{3}\right) \delta: 7.53(\mathrm{dd}, J=8.6,5.1 \mathrm{~Hz}, 1 \mathrm{H}), 7.30$ $(\mathrm{s}, 1 \mathrm{H}), 7.28-7.22(\mathrm{~m}, 2 \mathrm{H}), 7.21-7.12(\mathrm{~m}, 6 \mathrm{H}), 6.91(\mathrm{~d}, J=8.5$ $\mathrm{Hz}, 4 \mathrm{H}), 6.86(\mathrm{~d}, J=2.6 \mathrm{~Hz}, 2 \mathrm{H}), 6.51(\mathrm{~d}, J=8.7 \mathrm{~Hz}, 1 \mathrm{H}), 5.94$ (brs, $1 \mathrm{H}), 5.79-5.67(\mathrm{~m}, 3 \mathrm{H}), 5.56-5.47(\mathrm{~m}, 2 \mathrm{H}), 5.17$ (brs, $1 \mathrm{H}), 5.06(\mathrm{~s}, 1 \mathrm{H}), 4.96($ brs, $1 \mathrm{H}), 4.82-4.73(\mathrm{~m}, 2 \mathrm{H}), 4.43(\mathrm{tt}, J$ $=7.8,3.8 \mathrm{~Hz}, 1 \mathrm{H}), 4.39-4.28(\mathrm{~m}, 3 \mathrm{H}), 4.21(\mathrm{brs}, 1 \mathrm{H}), 4.13(\mathrm{brs}$, $1 \mathrm{H}), 3.78$ (s, 3H), 3.73 (q, $J=7.4 \mathrm{~Hz}, 5 \mathrm{H}), 3.67$ (brs, $1 \mathrm{H}), 3.48$ (ddd, $J=11.7,7.2,3.7 \mathrm{~Hz}, 2 \mathrm{H}), 3.41-3.28(\mathrm{~m}, 1 \mathrm{H}), 3.17(\mathrm{~s}, 1 \mathrm{H})$, 3.09 (ddd, $J=12.2,8.2,3.3 \mathrm{~Hz}, 2 \mathrm{H}), 2.80-2.60(\mathrm{~m}, 2 \mathrm{H}), 2.38-$ $2.15(\mathrm{~m}, 7 \mathrm{H}), 2.13-2.05(\mathrm{~m}, 2 \mathrm{H}), 1.93(\mathrm{ddd}, J=12.8,8.0,3.7$ $\mathrm{Hz}, 2 \mathrm{H}), 1.85-1.79(\mathrm{~m}, 2 \mathrm{H}), 1.54(\mathrm{~s}, 3 \mathrm{H}), 1.42(\mathrm{~s}, 9 \mathrm{H}), 1.34(\mathrm{~s}$, $3 \mathrm{H}), 1.04(\mathrm{~d}, J=2.8 \mathrm{~Hz}, 42 \mathrm{H}), 1.01(\mathrm{~s}, 6 \mathrm{H}), 0.96(\mathrm{~s}, 6 \mathrm{H}) ;{ }^{13} \mathrm{C}$ NMR $\left(101 \mathrm{MHz}, \mathrm{CDCl}_{3}\right) \delta: 162.1,162.0,159.6,159.5,156.2$, $155.8,150.9,150.4,142.80,142.78,136.88,136.86,135.23$, $135.21,133.9,133.6,131.33,131.30,131.29,129.40,129.37$, $129.2,129.1,129.02,128.98,126.24,126.22,126.21,125.40$, 125.36, 124.5, 124.4, 123.20, 123.19, 122.5 (2C), 121.8, 120.1, $119.3,116.8$ (2C), 115.4, 80.4, 80.02, 79.99, 79.96, 79.95, 79.92, $79.87,79.85,79.83,74.51,74.50,72.7,70.4,70.3,69.5,60.0,59.9$, 55.73, 55.72, 46.7, 46.19, 46.15, 46.13, 46.11, 46.10, 46.07, 46.0, $44.8,34.7,34.5,32.61,32.58,30.2,29.7,29.64,29.60,28.50$, 28.45, 28.42, 28.38, 28.34, 27.25 (2C), 27.19, 27.16, 25.31, 25.29, 25.27, 18.1 (12C), 14.1, 12.2, 11.9 (6C); HRMS $\left(\mathrm{ESI}^{+}\right) \mathrm{m} / z$ : calcd for $\mathrm{C}_{94} \mathrm{H}_{137} \mathrm{Cl}_{4} \mathrm{~F}_{3} \mathrm{~N}_{7} \mathrm{O}_{21} \mathrm{Si}_{2}[\mathrm{M}+\mathrm{H}], 1952.8112$; found, 1952.8098 .

Synthesis of 26. To a stirred solution of $\mathbf{2 5}(7.8 \mathrm{mg}, 4.0 \mu \mathrm{mol})$ and paraformaldehyde $(3.6 \mathrm{mg}, 0.12 \mathrm{mmol})$ in $\mathrm{CH}_{3} \mathrm{CN}(0.5 \mathrm{~mL})$ was added $\mathrm{NaB}(\mathrm{CN}) \mathrm{H}_{3}(7.5 \mathrm{mg}, 0.12 \mathrm{mmol})$. After being stirred for $17 \mathrm{~h}$ at $\mathrm{rt}$, the reaction mixture was quenched with saturated aq $\mathrm{NaHCO}_{3}$ and extracted with $\mathrm{CHCl}_{3}$. The combined organic extracts were dried over $\mathrm{Na}_{2} \mathrm{SO}_{4}$ and concentrated in vacuo. The crude product was purified by silica gel column chromatography (hexane/EtOAc 33:67) to afford 26 (4.7 mg, $2.4 \mu \mathrm{mol}, 59 \%$ ): TLC (hexane/EtOAc 20:80) $R_{\mathrm{f}}=0.50 ;{ }^{1} \mathrm{H}$ NMR (400 MHz, chloroform-d) $\delta$ : $7.57(\mathrm{~d}, J=8.8 \mathrm{~Hz}, 1 \mathrm{H}), 7.38$ (dd, $J=19.7,7.9$ $\mathrm{Hz}, 1 \mathrm{H}), 7.29$ (s, $1 \mathrm{H}), 7.22-7.10(\mathrm{~m}, 5 \mathrm{H}), 6.90(\mathrm{~d}, J=9.1 \mathrm{~Hz}$, $4 \mathrm{H}), 6.85(\mathrm{~d}, J=3.6 \mathrm{~Hz}, 2 \mathrm{H}), 6.51(\mathrm{~d}, J=5.1 \mathrm{~Hz}, 1 \mathrm{H}), 6.25(\mathrm{~d}, J=$ $27.7 \mathrm{~Hz}, 1 \mathrm{H}), 5.84(\mathrm{dd}, J=13.4,8.0 \mathrm{~Hz}, 1 \mathrm{H}), 5.55(\mathrm{~s}, 1 \mathrm{H}), 5.48$ (brs, 1H), 5.13 (brs, 1H), 5.09 (s, 1H), 4.99 (brs, 1H), 4.86 (d, J $=6.3 \mathrm{~Hz}, 1 \mathrm{H}), 4.74(\mathrm{~d}, J=7.0 \mathrm{~Hz}, 1 \mathrm{H}), 4.43(\mathrm{tt}, J=7.5,3.6 \mathrm{~Hz}$, $1 \mathrm{H}), 4.36-4.28(\mathrm{~m}, 4 \mathrm{H}), 4.20(\mathrm{dd}, J=8.6,3.5 \mathrm{~Hz}, 1 \mathrm{H}), 3.77(\mathrm{~s}$, $3 \mathrm{H}), 3.74(\mathrm{t}, J=6.5 \mathrm{~Hz}, 4 \mathrm{H}), 3.69-3.63(\mathrm{~m}, 2 \mathrm{H}), 3.51-3.42(\mathrm{~m}$, $4 \mathrm{H}), 3.29$ (d, $J=14.5 \mathrm{~Hz}, 1 \mathrm{H}), 3.08$ (ddd, $J=12.2,8.4,3.4 \mathrm{~Hz}$, $2 \mathrm{H}), 2.76-2.68(\mathrm{~m}, 1 \mathrm{H}), 2.61-2.51(\mathrm{~m}, 1 \mathrm{H}), 2.45(\mathrm{~s}, 3 \mathrm{H})$, 2.29-2.14 (m, 5H), 2.12-2.05 (m, 2H), 1.96-1.83 (m, 4H), $1.55(\mathrm{~s}, 3 \mathrm{H}), 1.39(\mathrm{~s}, 9 \mathrm{H}), 1.37(\mathrm{~s}, 3 \mathrm{H}), 1.26(\mathrm{~s}, 3 \mathrm{H}), 1.04(\mathrm{~d}, J=$ $4.6 \mathrm{~Hz}, 42 \mathrm{H}), 1.01(\mathrm{~s}, 6 \mathrm{H}), 0.99(\mathrm{~s}, 6 \mathrm{H}) ;{ }^{13} \mathrm{C} \mathrm{NMR}(101 \mathrm{MHz}$, $\left.\mathrm{CDCl}_{3}\right) \delta: 173.0,172.3,171.22,171.15,162.0,159.5,157.5$, $155.8,150.6,142.83,142.81,136.9,135.4,131.3,129.36,129.35$, $129.31,129.30,129.03,128.99,128.95,128.93,126.1,122.5$ (2C), 116.8 (2C), 116.6, 115.33, 115.29, 107.3, 106.9, 84.1, 79.30, 79.28, 79.26, 79.24, 79.23, 74.88, 74.87, 73.6, 72.83, 72.80,
$70.61,70.56,69.8,67.3,60.39,60.36,60.0,59.9,55.70$ (2C), 54.2, 46.6 (2C), 46.1, 46.0, 45.0, 44.9, 44.7, 43.1, 41.2, 32.61, 32.59, 30.33 (2C), 30.27, 30.25, 29.69, 29.67, 29.65, 29.60, 28.52, 28.45, $27.31,27.28,27.24,27.23,27.22,27.15,25.14,25.11,22.7,18.1$ (12C), 14.2, 14.1, 11.9 (6C); HRMS $\left(\mathrm{ESI}^{+}\right) \mathrm{m} / z$ : calcd for $\mathrm{C}_{95} \mathrm{H}_{139} \mathrm{Cl}_{4} \mathrm{~F}_{3} \mathrm{~N}_{7} \mathrm{O}_{21} \mathrm{Si}_{2}[\mathrm{M}+\mathrm{H}], 1966.8269$; found, 1966.8288 .

MIC Assays. M. smegmatis (ATCC 607), Klebsiella pneumoniae (ATCC 8047), Pseudomonas aeruginosa (ATCC 27853), Acinetobacter baumannii (ATCC 19606), S. aureus (BAA-1683), C. difficile (ATCC 43596), Enterococcus faecium (ATCC 349), Fusobacterium periodontium ATCC 33693), Bacteroides fragilis (ATCC 25285), Streptococcus pneumoniae (ATCC 6301), Bacillus subtilis (ATCC 6051), C. perfringens (ATCC 13124), Lactobacillus casei (ATCC 393), Lactobacillus acidophilus (ATCC 4356), and E. coli (ATCC 10798) were obtained from American Type Culture Collection (ATCC). A single colony of $M$. smegmatis was obtained on Difco Middlebrook $7 \mathrm{H} 10$ nutrient agar enriched with albumin, dextrose, and catalase. Single colonies of $P$. aeruginosa, K. pneumoniae, A. baumannii, S. aureus, E. faecium, and E. coli were grown on tryptic soy agar for $24 \mathrm{~h}$ at $37^{\circ} \mathrm{C}$ in a static incubator and cultured in tryptic soy broth until $\log$ phase to be an optical density (OD) of $0.2-0.5$. The OD was monitored at $600 \mathrm{~nm}$ using a 96-well microplate reader. A single colony of $C$. difficile was obtained on a brain-heart infusion (BHI) agar plate and incubated at $37{ }^{\circ} \mathrm{C}$ under anaerobic conditions for $48 \mathrm{~h}$. Seed cultures and larger cultures were obtained using a BHI broth. The flasks were incubated anaerobically for $48 \mathrm{~h}$ at $37{ }^{\circ} \mathrm{C}$ and cultured to mid-log phase $\left(\mathrm{OD}_{600}\right.$ 0.4). The other bacteria were cultured in the recommended conditions by ATCC. ${ }^{48}$ The inhibitors were dissolved in polyethylene glycol $300-\mathrm{H}_{2} \mathrm{O}(1 / 1$, a final concentration of $1 \mathrm{mg}$ per $100 \mu \mathrm{L}$ ). This concentration was used as the stock solution for all studies. Bacterial cultures were treated with serial dilutions of inhibitors and incubated at $37^{\circ} \mathrm{C}$ for $48 \mathrm{~h}$. The MIC was determined by a 96 -well plate reader (BioTek Synergy XT, Winooski, VT, USA) at 570 and $600 \mathrm{~nm}$. If necessary, viable bacteria in each well (96-well plate) were measured via CFUs on a BHI agar plate. The absorbance measurements were also performed using a BioTek Synergy XT (Winooski, VT, USA) 96-well plate reader at 570 and $600 \mathrm{~nm}$.

Cytotoxicity Assays. Cytotoxicity assays were performed using Vero monkey kidney (ATCC CCL-81) and HepG2 human hepatoblastoma cell (ATCC HB-8065) lines. Vero or HepG2 cells were cultured in $75 \mathrm{~cm}^{2}$ flasks and transferred to 96-well cell culture plates using ATCC-formulated Eagle's minimum essential medium containing $10 \%$ fetal bovine serum and penicillin-streptomycin. Serially diluted aliquots of each test compound at concentrations ranging from 0.78 to $200 \mu \mathrm{g} / \mathrm{mL}$ were added to the cells. Control compounds with known toxicity, such as tunicamycin, colistin, or tobramycin, were included on each plate. The plates were incubated, and cytotoxic effects were determined via the MTT assay.

Spore Preparation. C. difficile (ATCC 43596) was inoculated on a BHI agar plate and incubated at $37{ }^{\circ} \mathrm{C}$ under anaerobic conditions for 14 days. The spores were collected from the agar using sterile distilled water and purified according to the procedures described in the literature. ${ }^{17}$ The vegetative forms of C. difficile were killed upon heating at $50{ }^{\circ} \mathrm{C}$ for $30 \mathrm{~min}$. The prepared spores were suspended in sterile distilled water at $4{ }^{\circ} \mathrm{C}$.

Spore Viability Testing. A solution of test compound was added to a suspension containing $C$. difficile spores $\left(2 \times 10^{5}\right.$ $\mathrm{mL}^{-1}$ ), and the mixture was incubated at $37^{\circ} \mathrm{C}$ for $24 \mathrm{~h}$. The spore suspension treated with the test compound was 
centrifuged $(4700 \mathrm{~g})$, and the pellet was washed with sterile distilled water, plated on a $\mathrm{BHI}$ agar containing $0.1 \%$ sodium taurocholate (a germination agent), incubated at $37{ }^{\circ} \mathrm{C}$ for $48 \mathrm{~h}$ under anaerobic conations. The resulting colonies were counted.

MraY (MurX), WecA, and AglH Assays. Preparations of the membrane fractions from E. coli, M. smegmatis, and Hydrogenivirga spp. were performed according to the procedures previously described. ${ }^{27,33}$ Procedures for the purification of $\mathrm{MraY}$ and AglH and inhibitory assays using these phosphotransferases are described in the Supporting Information.

\section{ASSOCIATED CONTENT}

\section{S Supporting Information}

The Supporting Information is available free of charge on the ACS Publications website at DOI: 10.1021/acsomega.7b01740.

Some assay data, copies of NMR spectra, HPLC chromatogram of new compounds, and assay procedures (PDF)

\section{AUTHOR INFORMATION}

\section{Corresponding Author}

*E-mail: mkurosu@uthsc.edu. Phone: 901-448-1045. Fax: 901448-6940 (M.K.).

\section{ORCID}

Michio Kurosu: 0000-0003-0092-0619

\section{Present Address}

${ }^{\S}$ University of Michigan, 620 S State Street, Ann Arbor, MI 48104, USA.

\section{Notes}

The authors declare no competing financial interest.

\section{ACKNOWLEDGMENTS}

The National Institutes of Health is gratefully acknowledged for financial support of this work (grant GM114611). M.K. thanks the University of Tennessee Health Science Center for generous financial support (CORNET award). NMR data were obtained on instruments supported by the NIH Shared Instrumentation grant. The authors gratefully acknowledge Dr. Isaac Donkor (University of Tennessee) for useful discussions.

\section{ABBREVIATIONS}

THF, tetrahydrofuran; TFA, trifluoroacetic acid; $\mathrm{CH}_{2} \mathrm{Cl}_{2}$, methylene chloride; DMSO, dimethyl sulfoxide; DMF, N,Ndimethylformamide; $\mathrm{MeOH}$, methanol; EtOAc, ethyl acetate; $\mathrm{CHCl}_{3}$, chloroform; HRMS, high-resolution mass spectrometry; HPLC, high-performance liquid chromatography; TLC, thinlayer chromatography; $\mathrm{Bu}, n$-butyl; $\mathrm{Ts}$, $p$-toluenesulfonyl; DMAP, N,N-dimethyl-4-aminopyridine; Boc, tert-butoxycarbonyl; EDCI, 1-(3-dimethylaminopropyl)-3-ethylcarbodiimide hydrochloride; DIC, N,N'-diisopropylcarbodiimide; NIS, $N$ iodosuccinimide; NMO, $\mathrm{N}$-methylmorpholine; TIPS, triisopropylsilyl; Ph, phenyl; ATCC, American Type Culture Collection; MIC, minimum inhibitory concentration; FIC, fractional inhibitory concentration; MTT, 3-(4,5-dimethylthiazol-2-yl)2,5-diphenyltetrazolium bromide; OD, optical density; FBS, fetal bovine serum; NADPH, nicotinamide adenine dinucleotide phosphate; SAR, structure-activity relationship; C. difficile, Clostridium difficile; CDI, Clostridium difficile infection; CDAD, C. difficile-associated diarrhea; MraY, phospho-MurNAc-pentapeptide translocase (translocase I); WecA, polyprenyl phosphate-GlcNAc-1-phosphate transferase; AglH, dolichyl-phos- phate GlcNAc-1-phosphotransferase; DPAGT1, dolichyl-phosphate GlcNAc-1-phosphotransferase 1; CFU, colony-forming unit; BHI, brain-heart infusion medium; Vero cells, African green monkey kidney cells; Caco-2 cells, heterogeneous human epithelial colorectal adenocarcinoma cells; C. perfringens, Clostridium perfringens; S. aureus, Staphylococcus aureus; B. subtilis, Bacillus subtilis; S. pneumoniae, Streptococcus pneumoniae; $M$. smegmatis, Mycobacterium smegmatis; L. acidophilus, Lactobacillus acidophilus; L. casei, Lactobacillus casei; F. periodontium, Fusobacterium periodontium; B. fragilis, Bacteroides fragilis; A. baumannii, Acinetobacter baumannii; P. aeruginosa, Pseudomonas aeruginosa; K. pneumoniae, Klebsiella pneumoniae; E. coli, Escherichia coli

\section{REFERENCES}

(1) DePestel, D. D.; Aronoff, D. M. Epidemiology of Clostridium difficile infection. J. Pharm. Pract. 2013, 26, 464-475.

(2) Lessa, F. C.; Mu, Y.; Bamberg, W. M.; Beldavs, Z. G.; Dumyati, G. K.; Dunn, J. R.; Farley, M. M.; Holzbauer, S. M.; Meek, J. I.; Phipps, E. C.; Wilson, L. E.; Winston, L. G.; Cohen, J. A.; Limbago, B. M.; Fridkin, S. K.; Gerding, D. N.; McDonald, L. C. Burden of Clostridium difficile infection in the United States. N. Engl. J. Med. 2015, 372, 825-834.

(3) Kachrimanidou, M.; Malisiovas, N. Clostridium difficile infection: A comprehensive review. Crit. Rev. Microbiol. 2011, 37, 178-187.

(4) Setlow, P. Spore germination. Curr. Opin. Microbiol. 2003, 6, 550556.

(5) Howerton, A.; Patra, M.; Abel-Santos, E. Fate of ingested Clostridium difficile spores in mice. PLoS One 2013, 8, No. e72620.

(6) Rafii, F.; Sutherland, J. B.; Cerniglia, C. E. Effects of treatment with antimicrobial agents on the human colonic microflora. Ther. Clin. Risk Manage. 2008, 4, 1343-1357.

(7) Hunt, J. J.; Ballard, J. D. Variations in virulence and molecular biology among emerging strains of Clostridium difficile. Microbiol. Mol. Biol. Rev. 2013, 77, 567-581.

(8) Venugopal, A. A.; Johnson, S. Current state of Clostridium difficile treatment options. Clin. Infect. Dis. 2012, 55, S71-S76.

(9) Tenover, F. C.; Tickler, I. A.; Persing, D. H. Antimicrobial-resistant strains of Clostridium difficile from North America. Antimicrob. Agents Chemother. 2012, 56, 2929-2932.

(10) Tsutsumi, L. S.; Owusu, Y. B.; Hurdle, J. G.; Sun, D. Progress in the discovery of treatments for C. difficile infection: A clinical and medicinal chemistry review. Curr. Top. Med. Chem. 2014, 14, 152-175.

(11) Jarrad, A. M.; Karoli, T.; Blaskovich, M. A. T.; Lyras, D.; Cooper, M. A. Clostridium difficile drug pipeline: Challenges in discovery and development of new agents. J. Med. Chem. 2015, 58, 5164-5185.

(12) van Beurden, Y. H.; Nieuwdorp, M.; van de Berg, P. J. E. J.; Mulder, C. J. J.; Goorhuis, A. Ther. Adv. Gastroenterol. 2017, 10, 373381.

(13) Babakhani, F.; Bouillaut, L.; Gomez, A.; Sears, P.; Nguyen, L.; Sonenshein, A. L. Fidaxomicin inhibits spore production in Clostridium difficile. Clin. Infect. Dis. 2012, 55, S162-S169.

(14) Sorg, J. A.; Sonenshein, A. L. Chenodeoxycholate is an inhibitor of Clostridium difficile spore germination. J. Bacteriol. 2009, 191, 11151117.

(15) Bouillaut, L.; McBride, S.; Sorg, J. A.; Schmidt, D. J.; Suarez, J. M.; Tzipori, S.; Mascio, C.; Chesnel, L.; Sonenshein, A. L. Effects of surotomycin on Clostridium difficile viability and toxin production in vitro. Antimicrob. Agents Chemother. 2015, 59, 4199-4205.

(16) Egan, K.; Field, D.; Rea, M. C.; Ross, R. P.; Hill, C.; Cotter, P. D. Bacteriocins: Novel solutions to age old spore-related problems? Front. Microbiol. 2016, 7, 461

(17) Sorg, J. A.; Sonenshein, A. L. Inhibiting the initiation of Clostridium difficile spore germination using analogs of chenodeoxycholic acid, a bile acid. J. Bacteriol. 2010, 192, 4983-4990.

(18) Allen, C. A.; Babakhani, F.; Sears, P.; Nguyen, L.; Sorg, J. A. Both fidaxomicin and vancomycin inhibit outgrowth of Clostridium difficile spores. Antimicrob. Agents Chemother. 2013, 57, 664-667. 
(19) Stoltz, K. L.; Erickson, R.; Staley, C.; Weingarden, A. R.; Romens, E.; Steer, C. J.; Khoruts, A.; Sadowsky, M. J.; Dosa, P. I. Synthesis and biological evaluation of bile acid analogues inhibitory to Clostridium difficile spore germination. J. Med. Chem. 2017, 60, 3451-3471.

(20) Siricilla, S.; Mitachi, K.; Wan, B.; Franzblau, S. G.; Kurosu, M. Discovery of a capuramycin analog that kills non-replicating Mycobacterium tuberculosis and its synergistic effects with translocase I inhibitors. J. Antibiot. 2014, 68, 271-278.

(21) Mitachi, K.; Siricilla, S.; Klaić, L.; Clemons, W. M.; Kurosu, M. Chemoenzymatic syntheses of water-soluble lipid I fluorescent probes. Tetrahedron Lett. 2015, 56, 3441-3446.

(22) Wang, Y.; Siricilla, S.; Aleiwi, B. A.; Kurosu, M. Improved synthesis of capuramycin and its analogues. Chem.-Eur. J. 2013, 19, 13847-13858

(23) Kurosu, M.; Li, K.; Crick, D. C. A concise synthesis of capuramycin. Org. Lett. 2009, 11, 2393-2396.

(24) Aleiwi, B. A.; Schneider, C. M.; Kurosu, M. Synthesis of ureidomuraymycidine derivatives for structure activity relationship studies of muraymycins. J. Org. Chem. 2012, 77, 3859-3867.

(25) Mitachi, K.; Aleiwi, B. A.; Schneider, C. M.; Siricilla, S.; Kurosu, M. Stereocontrolled total synthesis of muraymycin D1 having a dual mode of action against Mycobacterium tuberculosis. J. Am. Chem. Soc. 2016, 138, 12975-12980.

(26) Ochi, K.; Ezaki, M.; Iwani, M.; Komori, T.; Kohsaka, M. FR900493 substance, a process for its production and pharmaceutical composition containing the same. Eur. Pat. Appl. 0333177 A2, March 15, 1989.

(27) Kimura, K.-i.; Bugg, T. D. H. Recent advances in antimicrobial nucleoside antibiotics targeting cell wall biosynthesis. Nat. Prod. Rep. 2003, 20, 252-273.

(28) Al-Dabbagh, B.; Mengin-Lecreulx, D.; Bouhss, A. Purification and characterization of the bacterial UDP-GlcNAc: Undecaprenyl-phosphate GlcNAc-1-phosphate transferase WecA. J. Bacteriol. 2008, 190, $7141-7146$.

(29) Mitachi, K.; Siricilla, S.; Yang, D.; Kong, Y.; Skorupinska-Tudek, K.; Swiezewska, E.; Franzblau, S. G.; Kurosu, M. Fluorescence-based assay for polyprenyl phosphate-GlcNAc-1-phosphate transferase (WecA) and identification of novel antimycobacterial WecA inhibitors. Anal. Biochem. 2016, 512, 78-90.

(30) McDonald, L. A.; Barbieri, L. R.; Carter, G. T.; Lenoy, E.; Lotvin, J.; Petersen, P. J.; Siegel, M. M.; Singh, G.; Williamson, R. T. Structures of the muraymycins, novel peptidoglycan biosynthesis inhibitors. J. Am. Chem. Soc. 2002, 124, 10260-10261.

(31) Kurosu, M.; Narayanasamy, P.; Crick, D. C. Synthetic studies toward the generation of uridine-amino alcohol-based small optimized libraries. Heterocycles 2007, 72, 339-352.

(32) Tanino, T.; Al-Dabbagh, B.; Mengin-Lecreulx, D.; Bouhss, A.; Oyama, H.; Ichikawa, S.; Matsuda, A. Mechanistic analysis of muraymycin analogues: A guide to the design of MraY inhibitors. $J$. Med. Chem. 2011, 54, 8421-8439.

(33) Winn, M.; Goss, R. J. M.; Kimura, K.-i.; Bugg, T. D. H. Antimicrobial nucleoside antibiotics targeting cell wall assembly: Recent advances in structure-function studies and nucleoside biosynthesis. Nat. Prod. Rep. 2010, 27, 279-304.

(34) Hirano, S.; Ichikawa, S.; Matsuda, A. Total synthesis of (+)-FR900493 and establishment of its absolute stereochemistry. Tetrahedron 2007, 63, 2798-2804.

(35) Siricilla, S.; Mitachi, K.; Skorupinska-Tudek, K.; Swiezewska, E.; Kurosu, M. Biosynthesis of a water-soluble lipid I analogue and a convenient assay for translocase I. Anal. Biochem. 2014, 461, 36-45.

(36) Wang, Y.; Kurosu, M. A new protecting group and linker for uridine ureido nitrogen. Tetrahedron 2012, 68, 4797-4804.

(37) Frantz, D. E.; Fässler, R.; Carreira, E. M. Facile enantioselective synthesis of propargylic alcohols by direct addition of terminal alkynes to aldehydes. J. Am. Chem. Soc. 2000, 122, 1806-1807.

(38) Ohtani, I.; Kusumi, T.; Kashman, Y.; Kakisawa, H. A new aspect of the high-field NMR application of Mosher's method. The absolute configuration of marine triterpene sipholenol A. J. Org. Chem. 1991, 56, 1296-1298.
(39) Kurosu, M.; Li, K. Highly efficient $O$-glycosylations with $p$-tolyl thioriboside and $p$-TolSOTf. J. Org. Chem. 2008, 73, 9767-9770.

(40) Kent, W. J. BLAT-The BLAST-like alignment tool. Genome Res. 2002, 12, 656-664.

(41) Nita-Lazar, M.; Noonan, V.; Rebustini, I.; Walker, J.; Menko, A. S.; Kukuruzinska, M. A. Overexpression of DPAGT1 leads to aberrant $\mathrm{N}$-glycosylation of E-cadherin and cellular discohesion in oral cancer. Cancer Res. 2009, 69, 5673-5680.

(42) Ishizaki, Y.; Hayashi, C.; Inoue, K.; Igarashi, M.; Takahashi, Y.; Pujari, V.; Crick, D. C.; Brennan, P. J.; Nomoto, A. Inhibition of the first step in synthesis of the mycobacterial cell wall core, catalyzed by the GlcNAc-1-phosphate transferase WecA, by the novel caprazamycin derivative CPZEN-45. J. Biol. Chem. 2013, 288, 30309-30319.

(43) Matsumoto, M.; Hashizume, H.; Tomishige, T.; Kawasaki, M.; Tsubouchi, H.; Sasaki, H.; Shimokawa, Y.; Komatsu, M. OPC-67683, a nitro-dihydro-imidazooxazole derivative with promising action against tuberculosis in vitro and in mice. PLoS Med. 2006, 3, No. e466.

(44) Le Lay, C.; Dridi, L.; Bergeron, M. G.; Ouellette, M.; Fliss, I. Nisin is an effective inhibitor of Clostridium difficile vegetative cells and spore germination. J. Med. Microbiol. 2016, 65, 169-175.

(45) Chilton, C. H.; Crowther, G. S.; Ashwin, H.; Longshaw, C. M.; Wilcox, M. H. Association of fidaxomicin with C. difficile spores: Effects of persistence on subsequent spore recovery, outgrowth and toxin production. PLoS One 2016, 11, No. e0161200.

(46) Paredes-Sabja, D.; Shen, A.; Sorg, J. A. Clostridium difficile spore biology: sporulation, germination, and spore structural proteins. Trends Microbiol. 2014, 22, 406-416.

(47) Alvarez, Z.; Lee, K.; Abel-Santos, E. Testing nucleoside analogues as inhibitors of Bacillus anthracis spore germination in vitro and in macrophage cell culture. Antimicrob. Agents Chemother. 2010, 54, 53295336.

(48) Moir, A.; Cooper, G. Spore germination. In The Bacterial Spore: from Molecules to Systems; Eichenberger, P., Driks, A., Eds.; ASM Press, 2015.

(49) Paredes-Sabja, D.; Shen, A.; Sorg, J. A. Clostridium difficile spore biology: sporulation, germination, and spore structural proteins. Trends Microbiol. 2014, 22, 406-416.

(50) Kevorkian, Y.; Shirley, D. J.; Shen, A. Regulation of Clostridium difficile spore germination by the CspA pseudoprotease domain. Biochimie 2016, 122, 243-254. 